\title{
Culture and Institutions
}

\section{Citation}

Alesina, Alberto, and Paola Giuliano. 2015. "Culture and Institutions." Journal of Economic Literature 53 (4) (December): 898-944. doi:10.1257/jel.53.4.898.

\section{Published Version}

doi:10.1257/jel.53.4.898

\section{Permanent link}

http://nrs.harvard.edu/urn-3:HUL.InstRepos:27759053

\section{Terms of Use}

This article was downloaded from Harvard University's DASH repository, and is made available under the terms and conditions applicable to Open Access Policy Articles, as set forth at http:// nrs.harvard.edu/urn-3:HUL.InstRepos:dash.current.terms-of-use\#OAP

\section{Share Your Story}

The Harvard community has made this article openly available.

Please share how this access benefits you. Submit a story.

Accessibility 


\title{
Culture and Institutions ${ }^{1}$
}

September 1st, 2014

\author{
Alberto Alesina \\ Harvard University and IGIER Bocconi \\ Paola Giuliano \\ UCLA Anderson School of Management
}

\begin{abstract}
A growing body of empirical work measuring different types of cultural traits has shown that culture matters for a variety of economic outcomes. This paper focuses on one specific aspect of the relevance of culture: its relationship to institutions. We review work with a theoretical, empirical, and historical bent to assess the presence of a two-way causal effect between culture and institutions.
\end{abstract}

${ }^{1}$ We thank Benjamin Friedman and Andrei Shleifer for useful conversations and Janet Currie, Steven Durlauf, and six anonymous referees for excellent comments. 


\section{Introduction}

Recent research demonstrates that cultural variables determine many economic choicesthey even affect the speed of development and the wealth of nations. ${ }^{2}$ Researchers are now striving to better understand the mechanisms.

In this paper, we investigate what we know about one specific mechanism: the relationship between culture and institutions. Both terms are often vague in the literature; we devote space to defining them properly, and we also sum up how various authors have defined them differently.

Culture and institutions are endogenous variables, determined, possibly, by geography, technology, epidemics, wars, and other historical shocks. Can any causal link between the two be established? How do culture and institutions interact?

One notable study - by Putnam et al. (1993), on social capital in Italy-illustrates how complex these issues are. Putnam and his colleagues took advantage of a natural experiment involving an institutional reform: in the early 1970s, Italy's central government established 15 new regional governments. ${ }^{3}$ Ideally, they would function identically throughout the country, but in practice they didn't. The discrepancy was most pronounced between the center-north and the south. Putnam and his colleagues hypothesized that the variance was due to regional differences in levels of cooperation, participation, social interaction, and trust—four key "social capital" traits. They argued that these regional differences_-dating back at least as far back as the 12th century-are a function of whether the given region had experienced the institution of free cities. Free cities developed a form of early participatory democracy, generating a feeling of belonging to a polity, whose functioning could guarantee both protection from aggression and the provision of public goods. As a result, citizens of free cities developed a deep sense of civic and cooperative behavior, a cultural trait they transmitted from generation to generation.

Guiso, Sapienza, and Zingales (2013) formally tested this hypothesis, finding considerable support for it. A contemporary Italian city's social capital, a "cultural" variable determining the success or failure of its institutions, correlates with its historical experience as a free city in the Middle Ages. Thus, an institutional variable, the free-city arrangement, influenced a long-lasting cultural change that still affects Italy's local governments. If cultural values were not so persistent,

\footnotetext{
${ }^{2}$ Several economics papers have investigated what are the cultural traits relevant for development, their persistence and their historical origins. Several surveys have analyzed some of these aspects [see Guiso, Sapienza, and Zingales (2006) and Fernandez $(2008,2011)]$. For an informal treatment of the question of how cultural values affect development, see Landes (1998).

${ }^{3}$ The reform, which implemented an article originally approved in the 1945 constitution, can be reasonably construed as independent of regional development.
} 
being a free city in the 12 th century would have nothing do with today's institutions. At the same time, this long-lasting cultural trait was sparked by early forms of local self-determination, an institutional feature.

The experience of a free city in the Middle Ages is clearly not an exogenous variable. For example, even within central and northern cities, there is variation regarding which cities could more easily become free, due to geographic features that made them more or less capable of defending themselves against the emperor. Like geography, many other factors could have determined the relative efficiency of local governments in Italy. Yet, the complex interaction between culture and institutions is interesting, regardless of the "ultimate" causes.

Those who study culture are well aware of the importance of institutions and, as we document below, they try as well as they can to isolate the effect of culture from institutionsprobably because the importance of institutions is fairly well established. ${ }^{4}$ Since cultural economics is in its infancy, those who write about institutions don't seem to worry much about whether institutions are well identified and isolated from cultural influences, which may be problematic. Some may argue that culture is a vague variable and difficult to measure. One of our ancillary goals here is to try to clarify these definitional issues.

The rest of our paper is structured as follows. In section 2, we define what culture means in the economic literature, and how it is measured. Many contributions to the literature since the last two surveys discuss the relevance of culture on economic outcomes. Thus, we provide a map of the main cultural traits used in economics and their correlations. We also provide definitions and measurements of formal institutions. In section 3, we scrutinize the relationship between culture and institutions, first by reviewing existing empirical and theoretical literature that shows how culture can affect formal institutions, and then by reviewing recent studies that show how formal institutions affect culture. Then, we document the interplay between culture and formal institutions and review the literature on how they jointly determine economic development.

\section{Definitions and measurement of culture and institutions}

\subsection{Definitions of culture}

Defining culture is an arduous task. We start by providing a definition, distinguishing between empirical and theoretical definitions of culture. The reason for the distinction is that the mapping between empirical and theoretical concepts is often not straightforward.

\footnotetext{
${ }_{4}^{4}$ Various controversies remain regarding how, where, and in what sense institutions matter. See Glaeser et al. (2004).
} 
On the empirical side, most papers (if not all) follow the definition adopted by Guiso, Sapienza, and Zingales (2006), where culture is defined as "those customary beliefs and values that ethnic, religious, and social groups transmit fairly unchanged from generation to generation." Empirical papers, therefore, combine values and beliefs in the same definition.

On the theoretical side, values and beliefs are often treated differently. Several authors have developed models in which culture means beliefs about the consequences of one's actions, but where these beliefs can be manipulated by earlier generations or by experimentation. For example, Guiso, Sapienza, and Zingales (2008b) show how individual beliefs are initially acquired through cultural transmission and then slowly updated through experience, from one generation to the next. They use an overlapping generation model, in which children absorb their trust priors from their parents and then, after gaining real-world experience, transmit their updated beliefs to their own children. In this setting, multiple equilibria are possible. In the no-trust-no-trade equilibrium, beliefs of mistrust are transmitted from parents to children, who eventually shun trade and therefore do not learn about the trustworthiness of the population. Conversely, in the high-trust-high-trade equilibrium, parents transmit trust beliefs to their children, which encourages trade and learning about the true trustworthiness in the population. A temporary shock to trust can move a society permanently from one equilibrium to the other. Greif (1994) integrates game-theory and sociological concepts to define the relevance of cultural beliefs. In his view, "sociologists and anthropologists consider the organization of society to be a reflection of its culture, an important component of which is cultural beliefs. Cultural beliefs are the ideas and thoughts common to several people that govern interaction-between these people and between them, their gods, and other groups-and differ from knowledge in that they are not empirically discovered or analytically proved. In general, cultural beliefs become identical and commonly maintained, and communicated." Greif asserts there is a subset of "rational cultural beliefs, which capture people's expectations with respect to actions that others will take in various contingencies. ... Past cultural beliefs that sustain Nash equilibria provide focal points in repeated social interactions or when there are multiple equilibria." 5

Still others view culture as a more primitive phenomenon embodied in values and preferences (see, for example, Akerlof and Kranton, 2000). This definition, also used in psychology (Pinker, 1997; Kaplow and Shavell, 2007) emphasizes the role of emotions in motivating human

5 The importance of focal points was also recognized by Schelling (1960), who describes “focal points for each person's expectation of what the other expects him to expect to be expected to do." 
behavior.

The two interpretations are not mutually exclusive. Benabou (2008) shows that values and beliefs interact systematically. He incorporates "mental constructs" into a political-economy model and shows that these mental constructs interact with institutions to generate different beliefs, which could persist over time.

Empirical investigation of the relevance of culture on economic outcomes is fairly new in economics. So far, the goal of most cultural economics papers has been to establish the relevance of culture. Economists have devoted scant attention to disentangling differences between a belief and a value component. The term culture, thus far, has been ambiguous, indicating both values and beliefs. $^{6}$

For example, views differ on inequality and redistribution. Luttmer and Singhal (2011) highlight the "value component" and show a strong cultural persistence in the formation of preferences for redistribution by documenting a correlation between preferences for redistribution among second-generation immigrants and preferences for redistribution in the country of origin. ${ }^{7}$ Meanwhile, Alesina and Fuchs-Schündeln (2007) and Giuliano and Spilimbergo (2014) have shown that preferences for redistribution can be affected by political regimes or macroeconomic shocksemphasizing the beliefs aspect of culture.

Similar ambiguity exists in recent studies of the role of women in society. Alesina, Giuliano, and Nunn (2013) emphasize the value components of attitudes about women's participation in the labor force, by showing a strong correlation between female labor force today and female participation in agriculture in preindustrial societies; the origin of which originated in differences in

\footnotetext{
${ }^{6}$ Culture is a relevant concept in many other disciplines. An important paper in anthropology (Geertz, 1973) posits that culture is "a historically transmitted pattern of meanings embodied in symbols, a system of inherited conceptions expressed in symbolic forms by means of which men communicate, perpetuate, and develop their knowledge about and their attitudes toward life." Kinship, too, has been seen as a symbolic system and social institution. Another view in anthropology (Boyd and Richerson, 1985, 2005) is perhaps closer to the definition in economics. The authors define culture as decision-making heuristics or rules of thumb that have evolved to serve our need to make decisions in complex and uncertain environments. Using theoretical models, the authors show that if acquiring information is either costly or imperfect, using heuristics or rules of thumb in decision making can arise optimally. By relying on general beliefs, values, or gut feelings about the right thing to do in different situations, people may not always behave optimally, but they do save on the costs of obtaining information they need to always behave optimally. Culture refers to these decision-making heuristics, which typically manifest themselves as values, beliefs, or social norms. If decisionmaking heuristics manifest themselves as values, beliefs, or social norms, this definition could be similar to the one used in empirical papers such as Guiso et al. (2006).

${ }^{7}$ Alesina and Glaeser (2004) relate this view to long-lasting differences in views about poverty that differentiate, for instance, Americans from Europeans.
} 
agricultural technologies hundreds of years ago. ${ }^{8}$ Meanwhile, Fogli and Veldkamp (2011) and Fernandez (2013) emphasize a beliefs component to explain the increase in female labor-force participation over time. These two papers-which independently investigate how changes in culture generate changes in female labor-force participation over time-present a dynamic model of culture in which people hold heterogeneous beliefs regarding the relative long-run payoff for women who work in the market versus those who work at home. Both papers conclude that female labor-force participation has increased over time as beliefs evolve due to intergenerational learning.

\subsection{Definitions of formal institutions}

North (1990) defines institutions as "the humanly devised constraints that structure human interactions. They are made up of formal constraints (rules, laws, constitutions), informal constrains (norms of behavior, convention, and self-imposed codes of conduct), and their enforcement characteristics." In North's theory, formal rules are created by the polity, whereas informal norms are "part of the heritage that we call culture." Institutions, he says, are "the rules of the game." Acemoglu, Johnson, and Robinson (2006) define institutions as mechanisms through which social choices are determined and implemented; they distinguish between economic institutions and political institutions. The latter are mechanisms for the distribution of political power across different socioeconomic groups. Political power, in turn, determines economic institutions. For example, in Acemoglu (2003) institutions are represented by an indicator denoting which political pressure group in a given set has the power to control social choice. Institutional change is then the result of voluntary concessions by the controlling group, possibly under the threat of social contract.

Greif (2006a) defines an institution as "a system of social factors that conjointly generates a regularity of behavior"-by "social factors," he means "man-made, nonphysical factors that are exogenous to each person they influence," including "rules, beliefs, norms, and organizations."

The two definitions are somewhat related, with one main difference. In North's definition, the rules of the game are distinct from the way the game is played. Greif, on the other hand, does not regard institutions as exogenously specified rules. Instead, he treats institutions as endogenous,

\footnotetext{
${ }^{8}$ For another example on how differences in technology can affect norms, see Fernandez-Villaverde et al. (forthcoming). The authors construct a model of altruistic parents exercising a direct socializing effort on their daughters, at a cost, that rationalizes how technological improvement in contraception leads to a greater incidence in premarital sex and to a change in sexual mores.

${ }^{9}$ Cultural differences are not the only factors that explain female labor-force participation. The literature highlights competing stories, such as the importance of technological progress in home production, like the dishwasher (Greenwood, Seshadri, and Yorugoklu, 2005), or medical progress (Albanesi and Olivetti, 2009). For other explanations of changes in female labor-force participation, see Galor and Weil (1996), Costa (2000), and Goldin and Katz (2002). For a summary of the history of female labor-force participation, see Goldin (1990).
} 
emphasizing that the behavior of actors who enforce the rules of the game must be explained by institutions. According to Greif, institutions represent equilibria of a game rather that the rules of the game.

The problem with both definitions of institutions is that they overlap too much with culture, as "norms" and "conventions" are used to define both institutions and culture. This is especially true for Grief's definition, which we find too broad and hard to quantify.

Given this ambiguity, measuring culture and institutions separately would be possible only if one counts formal institutions (formal legal systems, formal regulation) as institutions. Thus, when we describe our measurement and when we review the literature on the interaction between culture and institutions, we refer to culture as values and beliefs (one could say informal rules) and to institutions as formal institutions. (This approach is also followed in most of the empirical papers trying to disentangle the two concepts.)

Semantically speaking, we find it counterproductive and confusing to label culture (meaning values and beliefs) as informal institutions. We find it confusing to label "everything"-from, say, the level of reciprocal trust in a society to constitutional rules about voting systems-as institutions. Clearly — this is the crux of our paper-culture (or informal institutions) and formal institutions are interrelated, but the label "informal institutions" implies that formal institutions determine informal ones and that the latter are of secondary importance. Once we agree that formal and informal institutions interact, and that either one may cause the other, then identifying certain values and beliefs as culture or informal institutions becomes merely a matter of semantics. We prefer the term culture over informal institutions; we find it more appropriate and less confusing. Similarly, for brevity, we sometimes refer to formal institutions simply as institutions. Formal and informal institutions (or culture, as we prefer to call them) can be complementary and can interact. Think, for instance, about legal formal institutions and trust. The former work better in a society with a high level of trust, at the very least because with more trust comes less litigation. Or, different cultural traits about the family and the relationships between its members affect the legal organization of the welfare state. In fact, the main theme of the present paper is precisely the study of the interaction between formal institutions and culture.

\subsection{Measurement}

Economists have measured culture in three ways: by using survey data; by looking at second-generation immigrants to isolate the impact of culture, holding constant the economic and institutional environment; and by collecting experimental evidence. Fernandez (2008) details the 
three approaches at length. We discuss them briefly below, then turn our attention to survey data, the most commonly used method for studying the interaction between culture and institutions. ${ }^{10}$

The most common tool for measuring culture is through survey questions ${ }^{11}$ : the answers to which are aggregated at the country level to measure values and beliefs. ${ }^{12}$ These country-level summaries are then correlated with economic outcomes (see Knack and Keefer, 1997, for the relationship between trust and income).$^{13}$ Drawbacks to this approach include reverse causality and omitted variables. Economists have tried solving these problems in several ways, with varying success: Gorodnichenko et al. (2013a, 2013b), Guiso et al. (2009), and Alesina et al. (2013)) used instrumental variables, though the exclusion restriction has been problematic. Tabellini (2010) and Duranton et al. (2009) constructed cultural variables at the regional level, using country fixed effects to capture omitted cross-country differences. Tabellini (2010) has also used regional instruments to solve the problem of reverse causality and omitted variables at the regional level; however, despite progress, this does not solve the exclusion restriction problem. Alesina et al. (2013) went one step further, not only examining variation across countries and subnational districts but also using within-country variation controlling for subnational-district fixed effects. ${ }^{14}$

The second way of measuring the role of culture, holding institutions constant, is to look at the way immigrants from different countries behave in the same destination country, typically (but not always) the United States. This approach should capture vertical transmission of cultural traits. ${ }^{15}$ The literature has been using mostly second-generation immigrants, who constitute a more appropriate sample than first-generation immigrants because issues of disruption and selection due

\footnotetext{
${ }^{10}$ Many recent papers have investigated the historical determinants of culture. Nathan $(2009,2013)$ summarizes the main determinants in six different groups: historical U.S. migration, traditional farming practices, the slave trade, European history, religion, and early-childhood experiences or various episodes in a person's life. See Nunn $(2009,2013)$ for all the relevant references.

${ }^{11}$ The World Values Survey is the tool most commonly used for cross-country comparison. Other barometers-the Latino Barometer, Asian Barometer, Eurobarometer, and Afrobarometer, for example-focus on specific regions of the world. For the United States, it's the General Social Survey.

${ }^{12}$ Another approach to calculating culture at the country level consists of taking the coefficients of the country fixed effects of a regression where the left-hand-side variable is the cultural value/belief after controlling for various individual-level characteristics. This approach solves concerns that the country-level average fails to capture the age composition of the population, differences in human capital, and so on.

${ }^{13}$ Most papers, starting from Knack and Keefer (1997), follow this strategy. For a review, see Guiso et al. (2006). For other more recent examples, see Aghion et al. (2010), Alesina et al. (forthcoming), Alesina and Giuliano (2010, 2011b, 2013), Alesina, Giuliano, and Nunn (2013), Galasso and Profeta (2012), Guiso et al. (2009), Luttmer and Singhal (2011), Pinotti (2012), and Gorodnichenko et al. (2013a, 2013b).

${ }^{14}$ The authors use evidence from eight different census datasets, linking each ethnic group to its historical agricultural technology. As the link with culture is made at the individual level, they can control for subnational district characteristics.

${ }^{15}$ See Bisin and Verdier (2001) for a model of vertical transmission and Bisin and Verdier (2011) for a general review of various channels of cultural transmission.
} 
to migration are more attenuated. Though the issue of selection due to migration is mitigated, it could still be a concern. Different groups immigrated for different reasons and at different times, hence the nature of self-selection differs. Most papers discuss how the nature of self-selection biases the results.

This approach involves running regressions where the left-hand-side variable is the outcome among second-generation immigrants and the dependent variable is the same outcome in the country of origin. The regressions show the relevance of culture, holding institutions constant, since immigrants face the same institutional environment. Persistence of cultural traits among secondgeneration immigrants has been found for female labor-force participation (Alesina and Giuliano, 2010; Fernandez and Fogli, 2010). ${ }^{16}$ Giuliano (2007) shows that living at home with parents is also a cultural trait that immigrants bring with themselves. Luttmer and Singhal (2011) look at preferences for redistribution and find that immigrants from societies where the welfare state is more generous maintain those preferences in their destination countries. ${ }^{17}$ Grosjean (forthcoming) shows that crime levels in U.S. counties today correlate to the settlement of the counties by herders from Scotland. The percentage of Scottish-Irish immigrants is a proxy for the prevalence of a "culture of honor" and the associated violence that were transmitted from generation to generation. In this case, the percentage of immigrants of a certain origin can be seen as a proxy for certain cultural beliefs. ${ }^{18}$

By observing people from different countries in the same institutional environment, the evidence coming from the study of second-generation immigrants shows that some cultural traits travel with people when they move to a society with different institutions and values. Therefore, cultural values are persistent; when immigrants move to a place with different institutions, overwhelmingly their cultural values change gradually, if ever, but rarely within two generations.

Giavazzi et al. (2014) go further, presenting evidence on the speed of evolution (or lack thereof) of a wide range of values and beliefs of different generations of European immigrants to the United States. This paper is the first to provide evidence of transmission beyond the second generation. They find that persistence differs greatly across cultural attitudes. Moreover, their study

\footnotetext{
${ }^{16}$ Fernandez and Fogli (2010) find similar results for fertility.

${ }^{17}$ The authors use data from the European Social Survey and study immigrants in 26 destination countries.

${ }_{18}$ On the relationship between a culture of honor in the United States and the presence of Scottish-Irish immigrants, see Nisbett et al. (1996). A different view on the culture of honor in the South is proposed by Wyatt-Brown (1982, 2001). The author sees the ethos of honor at the heart of the traditional southern culture. According to the author, the defense of slavery was compelled by commitment to honor and duty and cannot be explained simply by material interests and racial imperatives. Christian religious thoughts and sentiments were also central to southern life (proslavery arguments often drew on biblical literalism). These pillars of race and religion in turn supported secession and strengthened the will to fight in the Civil War. The legacy of dishonor and humiliation that came with the Confederate defeat gave rise to the white racist rage that erupted in the 1890s.
} 
of higher-generation immigrants supports both evolving and persistent traits, while limiting the analysis to the second generation unduly emphasizes persistence. Further research is needed to understand which cultural traits persist (and why) and which tend to disappear more quickly.

Experimental evidence-the third tool for measuring the role of culture-has shown how people from different cultures behave differently when playing trust, public good, and ultimatum or dictator games. The classic reference is Henrich et al.'s (2001) study of small-scale societies. A critical issue with the experimental evidence is the external validity: How much can be generalized by games played with small groups and extrapolate general conclusions from them about a country, an ethnic group etc.?

Experiments constitute an additional resource to measure cultural values such as trust, in addition to the subjective measures that can be obtained by survey data. We will review this literature more closely in section 3, where we look at the interaction between culture and institutions.

We turn our attention now to the cultural traits that have so far received the most attention in the empirical literature. In describing these variables, we refer to culture as both preferences and beliefs, without distinguishing between the two; this is the approach taken in most papers that used these measures.

\section{Generalized trust}

The most studied cultural trait is generalized trust toward others, where others refers to people the respondent does not know. ${ }^{19}$ The importance of this trait cannot be overemphasized. Arrow (1972) writes, "Virtually every commercial transaction has within itself an element of trust, certainly any transaction conducted over a period of time. It can be plausibly argued that much of the economic backwardness in the world can be explained by the lack of mutual confidence."

This variable is measured in two ways: with surveys and laboratory experiments. In surveys, the question typically is, "Generally speaking, would you say that most people can be trusted or that you can't be too careful when dealing with others?" Possible answers are typically either, "Most people can be trusted" or "Need to be very careful." This question can be found in such surveys as the World Values Survey (WVS), the General Social Survey (GSS), and the European Social Survey,

\footnotetext{
${ }_{19}$ Many surveys ask questions regarding trust toward various institutions such as parliaments, governments, large corporations, and banks. While in part the response to these questions may reflect cultural biases, they may simply measure the efficiency or corruption of these institutions. We don't consider these variables in this paper. We discuss the issue of trust within a family, in the context of our treatment of cultural values regarding the family.
} 
and in most of the Barometers (the Latino Barometer, the Afrobarometer, the Asian Barometer, etc.). ${ }^{20}$

Individual characteristics such as education are positively correlated with trust. Historically discriminated-against minorities (African Americans, for one) have lower levels of generalized trust (Alesina and La Ferrara, 2000). Uslaner (2005) has shown that trust is a moral value, a persistent individual feature that doesn't depend much on life experiences. ${ }^{21}$

Trust travels less well across than within racial or nationality groups. The level of trust is lower in ethnically diverse U.S. cities (Alesina and La Ferrara, 2000, 2002) and neighborhoods (Putnam, 2000). Also, people tend to trust members of their own nationality more than they trust foreigners (Guiso, Sapienza, and Zingales 2009). ${ }^{22}$

Trust affects economic development (Knack and Keefer, 1997), individual performance (Butler et al., 2014), ${ }^{23}$ financial development, participation in the stock market, and trade (see Guiso, Sapienza, and Zingales, 2004, 2008a, 2009), innovation (Fukuyama, 1995), and firm productivity (Bloom, Sadun, and Van Reenen, 2012; La Porta et al., 1997). For a review of the impact of trust on various economic outcomes, see Algan and Cahuc (2013).

The second way of measuring trust is with experiments, primarily trust games. The most common is a two-player, sequential-moves game of perfect information in which the first mover, the "sender," endowed with some fixed amount of money, chooses how much money to send to the second mover, the "receiver." Any money sent is increased by the experimenter according to a

\footnotetext{
${ }^{20}$ In most studies, this measure has been used as a proxy for social capital, i.e., "those persistent and shared beliefs and values that help a group overcome the free rider problem in the pursuit of socially valuable activities" (see Fukuyama, 1995; Putnam, 2000; and Guiso et al., 2011). Another definition of social capital involves its relationship with networks. Coleman (1988), for example, discusses closure in social networks, emphasizing the ability of small groups to monitor and pressure each other to behave. According to the closure argument, social capital is created by a network of strongly interconnected elements. A broader view of social capital is summarized in Durlauf and Fafchamps (2005), who distinguish "three main underlying ideas: (1) social capital generates positive externalities for members of a group; (2) these externalities are achieved through shared trust, norms, and values, and their consequent effects on expectations and behavior; (3) shared trust, norms, and values arise from informal forms of organizations based on social networks and associations. The study of social capital is that of network-based processes that generate beneficial outcomes through norms and trust."

${ }^{21}$ He supports his claim by using two panel surveys-the 1972-74-76 American National Election Study (ANES) and the 1965-1973-1982 Parent-Child Socialization Study. Two-thirds of young people and more than $70 \%$ of their parents were consistent trusters or mistrusters.

${ }^{22}$ These authors also show that this feature of trust may explain various forms of "home bias" observed in portfolio composition and various financial transactions.

${ }^{23}$ Whereas at the aggregate level a positive correlation exists between trust and economic development, at the individual level the relationship is hump-shaped. Butler et al. (2014) hypothesize that highly trusting people tend to assume too much social risk and thus be cheated more often, ultimately performing less well than people closer to the mean trustworthiness of the population. At the other end of the spectrum, people with overly pessimistic beliefs avoid being cheated but give up profitable opportunities, and thus underperform.
} 
commonly known function before being allocated to the receiver. The receiver then chooses to return any amount to the sender, ending the game. With purely own-money-maximizing players, the Subgame Perfect Nash Equilibrium of this one-shot game is simple: receivers never return any money and consequently senders never send any money. The sender's behavior is used as a measure of trust, whereas the receiver's behavior proxies for trustworthiness. Only with trust and trustworthiness can the pair hope to increase profits. In fact, in many such experiments people "trust" each other and cooperate. ${ }^{24}$

A large experimental literature has distinguished between trust toward fellow group members versus out-group members, and trust within and outside the clan. In myriad studies on trust toward group members versus out-group members-in which participants were divided into groups with trivially defined distinctions ${ }^{25}$ - participants were willing to share more money or cooperate more with in-group members than with out-group members (Eckel and Grossman, 2005; Charness, Rigotti, and Rustichini, 2007; Chen and Li, 2009; Chen and Chen, 2010; and Butler, 2013). The results are similar when people belong to groups defined according to deeply rooted distinctions. In a classic study of trust in the clan (Fershtman and Gneezy, 2001), participants play a trust game with opponents of distinct ethnic affiliations. The experiment took place in Israel, with two ethnic groups: Ashkenazic Jews, the descendants of European Jews, and Eastern Jews, the descendants of African and Asian Jews. The authors found that the amount of money transferred to Eastern Jews was significantly lower than that transferred to Ashkenazic Jews. Further, mistrust of Eastern Jews was common not only among Ashkenazic Jews but also among Eastern Jews themselves. $^{26}$

Cross-country studies find that people tend to trust their compatriots more than they do people from other nationalities (Guiso, Sapienza, and Zingales, 2009). The authors also highlight significant differences in how a certain country is "trusted" on average by foreigners, consistent with a trustworthiness interpretation of trust (Greeks, at the bottom of the distribution, are trusted much less than Swedes, who are near the top of the trust distribution). These differences in bilateral trust are crucial for explaining various types of international financial transactions and trade.

\footnotetext{
${ }^{24}$ For a discussion on the correlation between survey measures of trust and laboratory measures of trust, see Glaeser et al. (2000) and Fehr et al. (2002).

25 The experimental literature focuses on trivially defined distinctions (such as expressed preferences between pairs of abstract paintings by Klee and Kandisky) because the experimental method is driven by the search for the minimal group, or the weakest cohesion that will produce discriminatory behavior. The aim here is to understand whether group behavior is a generic human trait, rather than the outcome of blood, religion, or other deeply rooted traditions.

${ }^{26}$ Other studies on the trust game played among observable cultural groups are Bornhorst et al. (2010), Fershtman et al. (2005), and Willinger et al. (2003).
} 


\section{Individualism versus collectivism}

Several contributions (Greif, 1994; Gorodnichenko et al., 2013a, 2013b) have focused their attention on one specific dimension of culture: individualism versus collectivism. Many crosscultural psychologists consider this the main dimension of cultural variation across countries (Heine, 2008). Gorodnichenko and Roland (2013a) explain why individualism can be relevant for growth. By emphasizing personal freedom and achievement, individualism awards social status to personal accomplishments such as innovation. At the same time, this trait can make collective action more difficult because people pursue their own interests without internalizing collective interests. Collectivism, on the contrary, makes collective action easier, because people are more able to internalize group interests, but, by encouraging conformity, discourages innovation. To show that individualism is good for growth, the authors built an endogenous growth model that captures the trade-off between the two traits.

The commonly used measure for individualism comes from Hofstede (2001). Individualism, measured in different societies by interviewing IBM employees in 30 countries, indicates the degree to which people are integrated into groups. In individualistic societies, personal achievements and individual rights are stressed. People are expected to stand up for themselves and their immediate family, and to choose their own affiliations. In contrast, in collectivistic societies, people act predominantly as members of a cohesive, lifelong group or organization. ${ }^{27}$ Another measure of individualism has been developed by cross-cultural psychologist Shalom Schwartz (1992). He calls the measure of individualism "mastery," the importance of getting ahead by being self-assertive. ${ }^{28}$

\footnotetext{
27 In addition to individualism, Hofstede (2001) studies four other orthogonal cultural dimensions: power distance, masculinity, uncertainty avoidance, and long-term orientation. Power distance focuses on the degree of equality, or inequality, between people in a given country. It represents the extent to which the less powerful members of organizations and institutions accept that power is distributed unequally. Masculinity reflects the degree to which a society reinforces the traditional masculine-work role model of male achievement, control, and power. The assertive pole has been called "masculine" and the caring pole "feminine." Uncertainty avoidance captures a society's attitude toward uncertainty, while long-term orientation is associated with such values as thrift and perseverance as opposed to respect for tradition and fulfilling social obligation, which are associated with short-term orientation. Hofstede's measures have faced criticism, but they constitute by far the most used and cited cultural framework in international business, management, and applied psychology. Hofstede's cultural database has been expanded to almost 80 countries. The most current version of the data is available at http://www.geert-hofstede.com/.

${ }^{28}$ Schwartz (1992) identified a set of 45 individual values recognized across cultures, covering all value dimensions needed to explain intercountry cultural variation. He subsequently surveyed school teachers and college students from 67 countries, averaged the scores on each of the 45 values, and identified seven dimensions along which national cultures could differ. These dimensions are conservatism, intellectual autonomy, affective autonomy, hierarchy, egalitarian commitment, mastery, and harmony. Conservatism represents a culture's emphasis on maintaining the status quo, and on restraining actions or desires that may disrupt the solidarity of the group or the traditional order. Intellectual and affective autonomy refer to the extent to which people are free to independently pursue their own ideas and intellectual directions, and their affective desires, respectively. Hierarchy denotes the extent to which it is legitimate to distribute power, roles, and resources unequally. Egalitarian commitment refers to the extent to which people are inclined to
} 


\section{Family ties}

Another important cultural value is the relevance of family ties in society. Banfield (1958) and Coleman (1990) focus on different cultural traits regarding family values. Both authors notice that societies based on strong ties among family members tend to promote codes of good conduct within small circles of related persons (family or kin); in these societies, selfish behavior is considered acceptable outside the small network. On the contrary, societies based on weak ties promote good conduct outside the small family/kin network, enabling one to identify oneself with a society of abstract individuals or abstract institutions.

Alesina and Giuliano (2010) measure the strength of family ties using three WVS questions, capturing beliefs on the importance of the family in a person's life, the duties and responsibilities of parents and children, and the love and respect for one's own parents. This measure is used to study the impact of culture on a variety of outcomes, including labor-force participation of women, young adults, and the elderly; political participation; measures of generalized trust; household production; and geographical mobility (see Alesina and Giuliano, 2010, 2011b, 2013). Basically, societies that rely too much on the family have less generalized trust and lower civic sense. In addition, according to the "male breadwinner hypothesis," societies with strong family ties tend to have greater home production, mostly done by women, young adults, and older people. Additional measures of family ties can be derived by objective measures such as frequency of contact between family members or how close to the parents children live after they leave their parental house. For instance, in Spain, Greece, and Italy, about $70 \%$ of children live less than five kilometers from their parents' home, while in Denmark the figure is less than $30 \%{ }^{29}$

Strong family ties are also at the core of industrial structures based on family firms. Using a measure of family ties similar to the one used by Alesina and Giuliano (2010), Bertrand and Schoar (2006) show that in cultures with strong family ties, family capitalism is more common and a larger percentage of firms are family businesses. ${ }^{30}$ The authors show that this industrial structure is suboptimal: nepotism in hiring normally decreases the average quality of the firm; in addition, managers, who are normally family members, tend to be too risk-averse. Finally, on average, family

voluntarily put aside selfish interests to promote the welfare of others. Mastery expresses the importance of getting ahead by being self-assertive, while harmony denotes the importance of fitting harmoniously into the environment.

${ }^{29}$ See Alesina, Algan, Cahuc, and Giuliano (forthcoming).

${ }^{30} \mathrm{~A}$ family business is one in which a family holds control of a company, either by not trading it publicly or by holding a majority stake if it is publicly traded. See also Caselli and Gennaioli (2011) for evidence regarding inefficiencies in the management of family firms. 
firms tend to remain smaller. Several studies looking at European and Latin American countries show that, on average, family firms perform less well than nonfamily firms.

Greif $(2005,2006 \mathrm{~b})$ uses the distinction between nuclear family and extended kinship groups to study how the nuclear family in medieval times helped establish and grow corporations. Extended kinship groups helped facilitate trade and establish trust-based relationships. Greif and Tabellini (2012) show that the presence of the nuclear family in Europe as opposed to the clan (a group consisting of families that traced their patrilineal descent back to one common ancestor, who settled in a given locality) in China was a key to explaining divergent patterns of urbanization in Europe and China.

Todd $(1983,1990)$ argues that different forms of family structures explain the diffusion of or resistance to social changes in Europe, including Protestantism, secularism, and the acceptance and diffusion of communism. Todd characterizes family types along two dimensions: vertical and horizontal. The vertical relationship_-between parents and children-is either "liberal," if children become independent from their parents at an early age and leave their parental home as soon as they get married, or "authoritarian," if children continue to depend on their parents in adulthood and still live with them after marrying. The horizontal relationship_-between siblings—is either "egalitarian," when siblings receive an equal share of family wealth after their parents' death, or "non-egalitarian," when parents favor one offspring at the expense of the others and transmit family wealth only to one child.

Todd's two dimensions yield four possible types of family organization: the absolute nuclear family (liberal vertical relationship; non-egalitarian horizontal relationship), the egalitarian nuclear family (liberal; egalitarian), the stem family (authoritarian; non-egalitarian), and the communitarian family (authoritarian; egalitarian). ${ }^{31}$ Absolute nuclear families are widespread in the United States, the United Kingdom, Australia, New Zealand, the Netherlands, and Denmark. Egalitarian nuclear families are prevalent in Italy, Spain, Greece, Portugal, Romania, Poland, Latin America, and Ethiopia. Stem families are common in Austria, Germany, Sweden, Norway, the Czech Republic, Belgium, Luxembourg, Ireland, Japan, Korea, and Israel. Communitarian families are common in

\footnotetext{
31 Todd's family classification is based on historical monographs dating back to the Middle Ages, throughout Western Europe. These monographs were collected by the church or other legal powers to track their local population and levy taxes. When Todd combined these historical monographs with census data from the 1950s, he found that the four family arrangements have persisted throughout Europe since the Middle Ages.
} 
Russia, Bulgaria, Finland, Hungary, Albania, China, Vietnam, Cuba, Indonesia, and India. ${ }^{32}$ Todd provides no empirical analysis, but his historical narrative, with some descriptive statistics, describes the various family systems and how they could be related to political and economic outcomes.

Duranton et al. (2009) use Todd's classification of family ties to explain regional disparities across Europe in household sizes, educational attainment, social capital, labor-force participation, sectoral structure, wealth, and inequality. Galasso and Profeta (2012) use Todd's classification to show that family structures are crucial for explaining different types of pension systems, and that Todd's definition of nuclear and extended family is strongly correlated to the measure of family ties defined in Alesina and Giuliano (2010)..$^{33}$

Generalized morality

Tabellini (2008a, 2010) measures the relevance of generalized morality and limited morality in fostering economic development. "Limited morality" exists where cooperative behavior is extended only toward immediate family members; "generalized morality" exists where cooperative behavior is extended toward everyone in society. The idea comes from Platteau (2000), who posited that "in hierarchical societies, codes of good conduct and honest behavior are confined to small circles of related people (such as members of the family or the clan). Outside this small network, opportunistic and highly selfish behavior is regarded as natural and morally acceptable. By contrast, in modern democratic societies the rules of good conduct are valid in all social situations, not only in

\footnotetext{
32 In his provocative book On the Origin of English Individualism, Macfarlane (1978) distinguishes two "ideal types" of societies based on different family structures: the peasant society, based on the extended household, self-sufficient villages, limited geographical and social mobility, early marriage arranged by the family, high fertility because children are an economic asset, and patriarchal and communal moral values; and the modern society, based on the nuclear family, production for trade, interdependence of towns, controlled fertility, late marriage, and moral individualism. His main idea was that England displayed most of the features of modernity at least as far back as the 14th century. Therefore, there was no transition to modernity.

33 A voluminous literature in anthropology has focused on other types of societal organizations, such as the clan (a unilineal group of relatives living in one locality), the kin group (a collection of various clans that comprises "socially recognized relationships based on supposed as well as actual genealogical ties" [Winick, 1956, page 302]) or the ethnic group ("a group that entertains a subjective belief in their common descent because of similarities of physical type or of customs or both, or because of memories of colonization and migration. This belief must be important for group formation; furthermore it does not matter whether an objective blood relationship exists" [Weber, 1978, page 389]). For more on the relationship between kinship groups and economic outcomes, see La Ferrara and Milazzo (2011) on how kinship differences in inheritance rules can affect economic outcomes; Fafchamps (2000) and Fisman (2003) on how belonging to the same clan affects access to credit; Luke-Munshi (2006) on how belonging to the same clan increases the probability of employment and of finding high-paying jobs. For a review on the relevance of kinship ties in development, see La Ferrara (2010). Further, interesting experimental evidence shows how differences in kinship ties affect behavior in trust and ultimatum games. Barr (2004), for example, compared two groups of villages in Zimbabwe: a group of villages set up in 1997 as resettlements consisting almost entirely of unrelated households and a control group of non-resettled villages made up almost exclusively of kin. She found lower levels of trust in resettled villages, which she interprets as a result of lower density in kinship ties.
} 
a small network of friends and relatives." This idea is related to (possibly extended) family ties and also collectivist versus individualistic societies. ${ }^{34}$

To measure generalized morality, Tabellini (2008a) combines using a principal component analysis two questions taken from the WVS: a measure of generalized trust (as described above) and the value attached to respect for other people as a fundamental belief that should be transmitted from parents to children. In a companion paper, Tabellini (2010) combines questions on four measures, including trust, respect for other people, the importance of obedience as one of the qualities that parents should transmit to their children, and how much people feel they have free choice and control over their lives, compared to how much they feel that what they do has no real effect on what happens to them. Both measures of generalized morality are relevant in explaining economic development across countries and among regions of Europe.

His work is open to criticism: the WVS contains numerous questions, so it is fair to ask why Tabellini chose those precise questions. Also, as we discuss below, the concept of generalized morality seems a combination of attitudes such as trust and individualism.

\section{Attitudes toward work and the perception of poverty}

Cultural attitudes toward work are obviously crucial. The Weberian argument about the birth of capitalism in a sense relies on this trait: the Protestant revolution, according to Weber, implied a different attitude toward hard work and success in the current life relative to the Catholic doctrine predominant in Europe at the time. ${ }^{35}$ This belief is measured using a question from either the WVS or the GSS that typically asks about the relevance of hard work versus luck in determining success in life.

Recent research has emphasized different views about the role of hard work. Some people believe that hard work is the avenue to success, a road open to many, leading to relatively high social mobility. ${ }^{36}$ Others believe that success is determined mostly by luck and personal connections; where this belief persists, social mobility is low. These views tend to be deeply ingrained: people whose views differ may face the same reality and maintain for a long time different opinions about whether

\footnotetext{
${ }^{34}$ Greif and Tabellini (2012) associate generalized morality with the diffusion of the nuclear family in Europe and limited morality with China, where the clan was more diffused.

35 The idea that a Protestant work ethic determined the higher prosperity of Protestant regions has been recently disputed. Becker et al. (2009) find that it was the instruction in reading the Bible that generated Protestant prosperity through accumulation of human capital. Cantoni (forthcoming), using data on 272 cities in the German Lands of the Holy Roman Empire, find that Protestantism exerted no effect on economic growth. For a critical view of Weber's hypothesis, see Camic et al. (2004) and Gorski (2003).

36 Among OECD countries, social mobility (measured using estimates of the extent to which sons' earning levels correlate with those of their fathers) is low in the United Kingdom, Italy, the United States, and France. By contrast, it is comparatively high in the Nordic countries, Australia, and Canada.
} 
hard work is the key to success (Alesina and Glaeser, 2004). Several papers have shown that beliefs concerning the income-generating process could be central in determining forms of economic organization (Piketty, 1995; Benabou and Ok, 2001; Alesina, Glaeser, and Sacerdote, 2001; Benabou and Tirole, 2006; and Di Tella, Galiani, and Schargrodsky, 2007). Doepke and Zilibotti (2008) define a "middle class" belief using the work-versus-luck variable as well as a variable regarding the importance of thriftiness as a value to be transmitted to children. These authors argue, similarly to Weber, that these two values were relevant for stimulating industrialization and the demise of the landed aristocracy.

A related issue concerns views about poverty. One question from the WVS asks whether the respondent believes that the poor could become rich if they tried hard enough. ${ }^{37}$ This statement could also imply a moral judgment regarding the poor: are they lazy or unfortunate ${ }^{38}$ Alesina and Glaeser (2004) document the chasm between Americans and Europeans regarding attitudes toward the poor. They discuss the evolution of this difference, and they relate this difference to the relative generosity of the respective welfare states. They also emphasize that poverty is viewed with less sympathy when correlated with racial differences, namely when the poor are disproportionately racial (or, more generally, linguistic or religious) minorities. ${ }^{39}$

Alesina and Giuliano (2011a), using WVS data, show that expectations about social mobility are strongly correlated to views about the poor. Alesina and Glaeser (2004) argue that Americans' and Europeans' differing beliefs about this issue go a long way toward explaining why the European welfare state is so much more generous than the American one. They also investigate the origins of this difference.

\section{The relationships among cultural traits}

Cultural traits are clearly interconnected. For example, in defining generalized versus limited morality, Tabellini (2008a) claims that the notion of limited morality reaches back to "amoral familism," a term coined by Banfield (1958) in his study of a village in Southern Italy. According to Banfield, the concept of morality is valid only within the family, whereas amoral behavior is considered morally acceptable and justified when interacting with people outside the family. Strong family ties and limited morality are difficult to tease out if one follows this definition. Also,

\footnotetext{
${ }^{37}$ The WVS asks respondents their opinion about whether most people in the country have a chance of escaping from poverty or very little chance of escaping from it.

38 The WVS asks respondents their opinion about why some people in the country live in need. Two different opinions emerge: People are poor because of laziness and lack of will power, or people are poor because of an unfair society.

${ }^{39}$ For more on this point, see Alesina, Michalopoulos, and Papaioannu (2013).
} 
generalized morality and trust are often treated as synonymous (see Tabellini, 2008a; Glaeser et al., 2000; and Guiso et al.; 2006, 2008b), because high levels of trust are typically associated with high social capital and high civil capital. This is apparent in the generalized morality variable, whose principal component includes trust among the different measures.

Gorodnichenko and Roland (2014) try to compare certain culture traits by linking findings from social psychology to the economic literature. Using evidence from cross-cultural psychology (Heine, 2008, 2010; Oyserman et al., 2002), they argue that the individualism-collectivism cleavage is the single most relevant dimension of cultural traits. In cultural psychology, the differences between individualism and collectivism have deep roots that affect different forms of behavior: they relate to different visions of self, differences in cognitive behavior, behavioral and motivational differences, and relational differences. The crucial distinction is between the independent self and the interdependent self (Markus and Kitayama, 1991), which in turn is associated with different cognitive models and relational differences. For example, the independent self will tend to interact in the same way with everybody, whereas the interdependent self will interact differently with in-group people than with others with whom relationships are less important or frequent (the out-group). This difference could help explain why more generalized trust exists in individualistic cultures than in collectivistic cultures, or why individualistic and collectivistic societies have different family structures.

If one looks at the cross-country correlations among cultural traits (Table 1), most of them are correlated, though not perfectly, as one would expect. In one case, the high correlation is forced: the one between trust and generalized morality, since the latter includes trust among its components. In other cases-for instance, the one between family ties and individualism-the correlation is expected. 
Table 1. Correlations among cultural traits

\begin{tabular}{|c|c|c|c|c|c|}
\hline & $\begin{array}{c}\text { Family } \\
\text { ties }\end{array}$ & $\begin{array}{c}\text { Generalized } \\
\text { morality }\end{array}$ & Individualism & Trust & $\begin{array}{l}\text { Work- } \\
\text { luck }\end{array}$ \\
\hline Family ties & 1 & & & & \\
\hline Generalized morality & $-0.49 * * *$ & 1 & & & \\
\hline Individualism & $-0.48 * * *$ & $0.60 * * *$ & 1 & & \\
\hline Trust & $-0.57 * * *$ & $0.83^{* * *}$ & $0.50 * * *$ & 1 & \\
\hline Work-luck & $0.33^{* * *}$ & -0.08 & $-0.24 *$ & -0.02 & 1 \\
\hline
\end{tabular}

Data on individualism come from Hofstede (2001). The remaining variables are authors' calculations using five waves of the World Value Survey. Family ties is the principal component of three questions: one about how important the family is in one person's life (on a scale from 1 to 4); and two that ask respondents to agree with one of two statements: One does not have the duty to respect and love parents who have not earned it versus Regardless of what the qualities and faults of one's parents are, one must always love and respect them; and Parents have a life of their own and should not be asked to sacrifice their own well-being for the sake of their children versus It is the parents' duty to do their best for their children even at the expense of their own well-being. Generalized morality is the principal component of three questions: one taking a measure of trust (defined below) and two asking respondents whether respect and obedience are qualities that children should be encouraged to learn at home. For trust, respondents are asked, Generally speaking, would you say that most people can be trusted or that you can't be too careful when dealing with others? Possible answers are either Most people can be trusted or Need to be very careful. For work-luck, respondents are asked to choose between two statements: In the long run, hard work usually brings a better life or Hard work does not generally bring success; it is more a matter of luck and connections. ***, **, and * indicate significance at the 1\%, 5\%, and $10 \%$ level.

In Figure 1, world maps depict the geographical distribution of the various cultural traits. Northern European countries, together with the United States, Australia, and New Zealand, have high levels of trust, individualism, and generalized morality. The United States also emphasizes effort (as opposed to luck) as the main driver of economic success, a belief less prevalent in Northern European countries. Since this belief is strongly related to preferences for redistribution, the difference could be due to the vastly differing U.S. and European welfare systems (Alesina and Glaeser, 2004).

The Scandinavian countries exhibit the lowest measure of family ties while the measures for African, Latin American, and some Asian countries are among the highest. Southern Europe measures high, but not among the highest. Similarly, the United States appears to have strong family ties, though the magnitude of the score is driven mostly by the question on the importance of the family in a person's life and not by the questions on links between parents and children. Individualism is particularly high in the United States, Australia, and Northern Europe. ${ }^{40}$

Within each country, there is often substantial heterogeneity across regions. For instance, Guiso, Sapienza, and Zingales (2004), Tabellini (2010), and Alesina and Giuliano (2013) take advantage of regional differences regarding generalized morality, trust, and family values inside the regions of Italy, Europe, and the whole world, respectively. This regional heterogeneity is quite

\footnotetext{
${ }^{40}$ Italy, despite having strong family ties and a relatively low level of trust, appears to score high on this value, which is surprising.
} 
useful empirically, as we shall see below, since it allows studying the correlation of culture with various economic variables, holding national institutions constant. Regional variations, often large, also implicitly demonstrate that national institutions in general don't automatically generate a uniform culture, even though national rulers often try to enforce (sometimes aggressively) homogeneity on their regions and populations. ${ }^{41}$

\section{Measurement of (formal) institutions}

One of the most common measures of formal institutions is an index of protection against expropriation (see Acemoglu et al., 2001). These data, collected from Political Risk Services, report a value between 0 and 10 for each country and year, with 0 corresponding to the lowest protection against expropriation. Glaeser et al. (2004), however, object to this variable as a measure of institutions, arguing that it's an equilibrium outcome and not an institution. For example, democracies and dictatorships can exhibit the same level of "protection of property rights."

Other standard measures of formal political institutions include constraints on the executive and indices of democracy. Variables have also been constructed to measure the "quality of government"-broadly speaking, a measure of well-functioning of the public sector-such as control of corruption and efficiency of the bureaucracy.

Then there's the legal system. La Porta et al. $(1997,1998)$ provided a measure of legal rules governing investor protection for many countries using national commercial (primarily corporate and bankruptcy) laws. The authors argue that legal rules protecting investors varied systematically among legal traditions or origins, with the laws of common-law countries (originating in English law) being more protective of outside investors than the laws of civil-law (originating in Roman law), particularly French civil-law, countries. Subsequent research showed that the influence of legal origins on laws and regulations is not restricted to finance. Government ownership of banks (La Porta et al., 2002), the burden of entry regulations (Djankov et al., 2002), labor-market regulations (Botero et al., 2004) vary systematically across legal families.

Finally, regulatory institutions-such as labor-market regulations, regulations of markets for goods and services, antitrust laws, and various regulatory-environment indices-have been coded and assembled by the OECD, the World Bank, Djankov et al. (2002), and Botero et al. (2004), among others.

A good summary of the institutional qualities characteristics associated with governance is the World Bank's Worldwide Governance Indicator (WGI). The WGI, a report on six dimensions

\footnotetext{
${ }^{41}$ See Laitin (2007) and Alesina and Reich (2013) for discussions on this point.
} 
of governance for 215 countries from 1996 to 2011, ${ }^{42}$ found that institutional features are strongly correlated-at least 0.8 among the various WGI indicators. Easterly and Levine (2003) also show that they are strongly correlated with the standard measure of protection of property rights, one of the most used measures of institutions. ${ }^{43}$ As such, they are normally used interchangeably in the empirical analysis.

These measures of institutions have been widely used. Glaeser et al. (2004), however, emphasize some conceptual problems with them ${ }^{44}$ - they neither measure policy constraints nor are they stable; rather, they are measures of policy choices ${ }^{45}$ - and suggest ways to improve the way institutions are measured. For example, they suggest that constitutional measures would be a better measure because they constraint behavior and are more likely to be permanent. At the same time, they note that "it is possible that these constitutional measures are noisy, and it is certain that 'rules on the books' are different from what actually takes place in a country. But this is precisely the point: the institutional outcomes that scholars have used as measures of constraints have little to do with the constitutional constraints, raising doubts about the effectiveness of changing political rules."

From this proposition, it therefore seems that one should measure both de jure and de facto institutions and asses when they deviate. Glaeser et al. (2004) suggest some measures of institutions that could be appropriate: two dealing with electoral systems ("plurality" and "proportional representation") and two dealing with judicial constraints on government (“judicial independence" and "constitutional review"). The first two measures are motivated by the work of Persson and

\footnotetext{
42 These six dimensions are voice and accountability (the extent to which a country's citizens are able to participate in selecting their government, as well as freedom of expression, freedom of association, and a free media), political stability and absence of violence (measuring perceptions of the likelihood that the government will be destabilized or overthrown by unconstitutional or violent means, including politically motivated violence and terrorism), government effectiveness (about the quality of public services, the quality of the civil service, and the degree of its independence from political pressures; the quality of policy formulation and implementation; and the credibility of the government's commitment to such policies), regulatory quality (the ability of the government to formulate and implement sound policies and regulations that permit and promote private-sector development), rules of law (capturing perceptions of the extent to which citizens have confidence in and abide the rules of society, and in particular the quality of contract enforcement, property rights, the police, and the courts, as well as the likelihood of crime and violence), and control of corruption (the extent to which public power is exercised for private gain, including both petty and grand forms of corruption, as well as "capture" of the state by elites and private interests).

43 Various datasets, such as the Quality of Government Dataset, compiled by the Quality of Government Institute at Goteborg University, have combined numerous measures of institutional features (including property rights and rule of law) for a large set of countries from 1946 to the present.

44 The authors cite the International Country Risk Guide, the Governance Indicators of the World Bank, and the Polity IV measures.

45 The authors stress two relevant characteristics of institutions: that they constrain behavior and that they are permanent or stable.
} 
Tabellini (2003), and the second two are taken from La Porta et al. (2004). ${ }^{46}$ These objective measures are also only weakly correlated with the other institutional measures that the authors themselves criticize. These considerations should be taken into account when using institutional measures in the empirical analysis.

\section{The relationship between culture and institutions}

Generally, studies looking at the relationship between culture and institutions tend to isolate one causal aspect, favoring one of two directions. A more promising research agenda has, on the other hand, emphasized a feedback effect between the two-given this interdependence, both institutions and culture co-evolve, which can generate multiple stable equilibria with different sets of self-enforcing institutions and cultural norms. In this section, we first review the set of papers looking at univariate causal explanations; we then discuss the papers looking at the joint evolution of culture and institutions and their effect on economic activity.

\subsection{From culture to formal institutions}

\section{Historical narratives of the relevance of culture on formal institutions}

Several studies on the relevance of culture on institutions provide historical narratives of specific cases. Fischer (1989), studying the evolution of institutions in the United States, documents how cultural beliefs brought by the four migration waves of the original settlers generated stark differences in laws. First came the Puritans, arriving in Massachusetts from East Anglia. Known for valuing education and order, they introduced laws promoting universal education and justice, together with town meetings and town covenants mimicking those of their country of origin. Next came the Virginia Cavaliers, who settled in the Chesapeake Bay from the South and Southwest of England. Their beliefs emphasized group inequality as a natural state of the world; they introduced laws with low taxes and low government spending and placed little emphasis on education. The Quakers, who arrived next from England's North Midlands and settled in the Delaware Valley, revered personal freedom, and thus established institutions emphasizing equal rights and limited government intervention. The final wave, the Scottish-Irish, arrived from Northern England, Scotland, and Ireland, settling in the backcountry of the U.S. South. They believed in freedom from any constraint and, as a result, espoused minimal government intervention and a limited justice

\footnotetext{
${ }^{46}$ Judicial independence is the average of three components: (1) the tenure of highest ordinary court judges, the tenure of administrative court judges, and a dummy coded 1 if judicial decisions are a binding source of law. Constitutional review is the sum of the rigidity of constitutions and the extent of judicial review (none, limited, or full).
} 
system. Clearly, the beliefs brought to the United States by these four groups were crucial determinants in the establishment and subsequent development of the first institutions in the United States.

A second historical example is provided by Greif (1994), who analyzed the cultural differences between medieval Maghribi and Genoese traders. Maghribis held "collectivist" JudeoMuslim beliefs and norms, which led them to develop different institutions from their "individualistic" Christian counterparts. The prevalence of collective relationships within a closely knit, exclusive group implied for the Maghribis an informal enforcement mechanism and therefore the lack of effective legal contract enforcement. The Genoese society, characterized by individualistic cultural beliefs, experienced a higher demand for legal contract enforcement than the collectivistic, kin-based community of the Maghribi traders. The Genoese developed formal institutions, including codified contract laws, double-entry bookkeeping, bills of lading, and other precursors of modern business practices. In Greifs view, therefore, different cultural values gave rise to the feasibility of private alternatives to the public legal system as a basis for economic transactions.

A third example aims for a cultural interpretation of the development of political systems around the world. In a provocative book, Todd (1990) argues that the development of political systems around the world is a function of underlying values ingrained in people from an early age through family systems: parent-child relations within the family determine the attitude toward liberal or authoritarian ideologies, whereas egalitarian inheritance practices among siblings lead to egalitarian ideologies. The appeal of differing modern ideologies results from their mirroring the character of various family types; and such ideologies spread only so far as the geographical extent of the family systems with which they have similarities. This, in his views, should partially explain differences in ideologies around the world, including communism, Nazism, and Anglo-Saxon liberalism. Todd argues that communism prevailed in societies with communitarian families (vertically authoritarian; horizontally egalitarian) because people were accustomed at home to the same authoritarian system adopted by government institutions. On the other hand, the absolute nuclear family of England (liberal; non-egalitarian) was fertile ground for the development of nonegalitarian capitalism, individualism, and market freedom. ${ }^{47}$ Note the connection between Todd's

\footnotetext{
47 Todd's theory has never been tested formally and perhaps suffers from anthropological determinism. The literature on the diffusion of communism, is certainly more complex. Pipes (1994) had a different view on the popularity of Communism in the Soviet Union. His view was that the October Revolution was, rather than a popular general uprising, a coup foisted by a small number of intellectuals, which established a one-party dictatorship that was repressive from the
} 
argument regarding the extended egalitarian family and the prevalence of communism with the "collectivist" society in Greif (1994). In both cases, a horizontal line (the clan in Greif, the communitarian family in Todd) interferes with the value of individualism, which brought about modern forms of capitalism. Alesina and Glaeser (2004) also relate the lack of development of a communist party in the United States with, among other things, the culture of individualism and the views about poverty discussed above, similar to what proposed by Lipset and Marks (2001). ${ }^{48}$

By analyzing these three experiences, we begin to glean the effect of culture on institutions from a historical perspective. Several recent papers have pushed the historical analysis forward, undertaking more formal tests of the impact of culture on institutions. We review these papers below.

\section{The impact of culture on financial institutions}

Finance has been widely investigated to discern interaction between culture and institutions. The literature yields a critical insight: trust can fundamentally affect financial development. The main idea is that different levels of trust may imply different needs regarding investors' protection and other regulatory variables. Financial institutions cannot "cause" financial development if cultural variables work against it. The legal system can enforce financial contracts, but without trust it would be costly to involve courts in financial transactions. Thus, cultural values (especially trust) lead to the development of financial markets and meaningful regulation.

This argument is developed by Guiso, Sapienza, and Zingales (2004, 2008a, 2008b) in their examination of the role of trust in determining attitudes toward financial transactions and the development of financial markets - in short, the "financial depth" of a country. These papers provide a range of insights. First, trust is strongly related to how people invest and participate in financial markets. The variation is large within the same legal system; in fact, they analyze withincountry variation. For instance, use of cash, participation in the stock market, and use of bank loans versus loans from friends are all variables that affect the financial structure of a country, and these authors show that cultural values affect it much more than "standard" variables such as risk aversion.

start. Similarly, Figes' (1989) view is that younger and more literate peasants and migrant townsmen were the ones who became the rural bureaucrats of the Bolshevik regime. This view, however, is controversial. A series of scholars, under the influence of the French Annales School, has instead sustained the interpretation that the Russian Revolution was a movement from below. Note, however, that some similarity exists between Pipes and Todd. Pipes also argued in favor of the totalitarian school, which sees the Third Reich, the Soviet Union, and Fascist Italy as totalitarian regimes united by their antipathy toward democracy. In Todd's view, there is also some similarity among totalitarian regimes, whose ideologies are compatible with an authoritarian structure of the family.

48 In a similar vein, Sombart (1976) discusses reasons for the lack of a successful communist party in the United States. 
The authors also assert that, at the macroeconomic level, taking into account cultural values could shed light on several puzzles in finance. For instance, stock-market participation is higher in countries with a higher level of trust; differing levels of trust could therefore explain low participation rates in various countries. Also, they find that trust is much higher among citizens of the same country; thus, investors hold a higher percentage of domestic assets than they "should," based on pure theories of portfolio diversification. They also show that a bilateral matrix of trust across countries explains a remarkable amount of cross-border holding of equities and foreign direct investment.

How does this work relate to La Porta et al.'s $(1997,1998)$ emphasis on legal institutions as determinants of financial development? Perhaps this is an example of what Greif defines as the social equilibrium including a combination of legal institutions and cultural variables. The interaction of certain legal origins (Anglo-Saxon ones) and a high level of trust in those countries (as discussed above) lead to financial development.

Guiso, Sapienza, and Zingales (2004) also show that differences in bilateral trust across pairs of countries have strong explanatory power in a standard gravity equation for trade flows. This correlation is robust to the inclusion of legal origins and institutions. ${ }^{49}$ Obviously, issues of reverse causation are a first-order problem here. Bilateral trade may increase bilateral trust, rather than the other way around. The authors address this issue using instrumental variables. As an instrument for trust, they use commonality of religion and a measure of somatic distance. ${ }^{50}$ They also show an additional supporting piece of evidence: the correlation of bilateral trust and trade is strong for differentiated products and absent for standardized ones, like oil. Mutual trust is in fact more likely to be relevant only in markets where quality control, tastes, and diffusion of information are more important relative to a standardized market.

\section{The impact of culture on formal legal institutions}

\footnotetext{
${ }^{49}$ Differences in the legal system could originate, in turn, from differences in cultural values, such as religious beliefs. Kuran (2005) shows that Islamic inheritance laws were an obstacle to the formation of the modern corporation, as emerged in Italy during the Renaissance. Community-building was central to Islam's mission. At the birth of Islam, the Arabian Peninsula was divided into tribes bound together by blood ties. The strong bonds within one's own tribe implied that intertribal alliances formed for defensive purposes were inherently unstable, fostering insecurity and retarding wealth creation. Islam responded to this broad need by promoting communal bonds based on religion rather than descent. The formation of these communal bonds was guaranteed by the presence of the wars, a type of unincorporated trust. The reason for such an institution was based on the need to have an institution based on an individual instead of one involving self-governance by an organized group (like corporations during the Renaissance, for example.)

50 The measure of somatic distance is based on the average frequency of three specific traits in the indigenous population, taken by Biasutti (1954): height, hair color (pigmentation), and cephalic index (the ratio of the length and width of the skull).
} 
Licht et al. (2005) study whether laws on the books in different societies reflect the prevailing national culture. They find that national scores of cultural value dimensions correlate with indices of shareholder voting rights and of creditor rights. In particular, they find that a national culture that promotes assertiveness in reconciling conflicting interests and that promotes tolerance for the resulting uncertainty is consistent with using litigation to deal with economic conflicts. ${ }^{51}$ The authors also show that correlations between culture and legal rules hold regardless of other major characteristics of countries; that they are not due to a reverse causal impact of legal rules on culture ${ }^{52}$; and that they persist in the face of formal legal reforms. As a result, national culture may impede reforms and induce path dependence in corporate governance systems. ${ }^{53}$

Murrell et al. (2011), in studying 17th-century England, constructed annual data on cultural dynamics and institutional development. To construct measures on institutions, they used reports on 18th-century court decisions that cite the statutes and earlier cases used by judges to support decisions and by lawyers to litigate. The cultural variable reflects data on word usage in a catalog of publications (books, pamphlets) from the 17th century, the English Short Title Catalogue. The authors capture the diffusion of the Whigs—-who emphasized the virtues of freedom and sought to limit the powers of the monarchy-by tracing patterns in the use of words emblematic of that culture. The authors then use a vector error correction model, which relates changes in culture and institutions to each other and to deviations of each from their long-run relationship. The main finding is that cultural diffusion spurs the development of case and statutory law. Although the choice of cultural variable could be problematic-reporting words that are emblematic to the Whigs could be endogenous - the exercise is very interesting, one of the few that features a time series of both

\footnotetext{
${ }^{51}$ Culture is measured using data from Schwartz (1992) and Hofstede (2001). The authors test two hypotheses: (1) Greater reliance on concrete legal rules enforceable in the courts is stronger in nations high on the Schwartz cultural orientation of Mastery (which emphasizes assertiveness, venturing, and active determination of one's destiny) and low on his Harmony orientation (which opposes head-on confrontation and should therefore discourage embodying economic interests in strict legal form and enforcing them in court). These cultural emphases are compatible with empowering investors and encouraging them to fight for their rights. (2) Investors' legal rights are stronger in nations high on the Hofstede Individualism dimension and low on his Uncertainty Avoidance dimension. Individualism (versus Collectivism) legitimizes the pursuit of personal interests rather than deference to others' decisions and interests. Uncertainty Avoidance affects the way power in organizations is exercised. High Uncertainty Avoidance is consistent with empowering authorities who control, whereas low Uncertainty Avoidance is compatible with corporate constituencies ready to challenge one another with indeterminate outcomes.

52 The authors use episodes of British rule as an instrument for culture. The exclusion restriction is problematic for this case, as being ruled by Britain could have affected many outcomes, including the law.

${ }^{53}$ Stulz and Williamson (2003) also show that culture matters for investor rights. They used countries' predominant religion and language as proxies for culture. In particular, they show that religion is important for creditor rights but not for shareholder rights. Further, language and religion are important for enforcement of rights. They also show that culture and legal origin affect different aspects of financial development, finding that stock-market development depends on a country's legal origin, whereas debt markets and banking development depend on culture.
} 
culture and institutions, a much better framework than cross-country regressions for evaluating their interaction.

\section{The impact of culture on democracy}

Understanding the underlying causes of democratization is one of the key questions in social science. Lipset (1959) emphasized the importance of economic development. As a result, most of the empirical literature has focused on this specific determinant; however, it finds the relationship between development and democracy mostly a feature of cross-sectional data, and when performing panel data analysis, the correlation disappeared (see Acemoglu et al., 2008). Almond and Verba (1963) were the first to attempt to quantify the relevance of culture for democracy. They interviewed a sample of 1,000 people in five countries (the United States, Mexico, Great Britain, Germany, and Italy) and defined a measure of political attitudes. ${ }^{54}$ They argued that political culture is crucial to the operation of any political system. The study had several limitations, including a small sample size, a limited set of countries, and no discussion of reverse causality.

More recently, Gorodnichenko and Roland (2013b) studied the importance of culture as a determinant of democratization. The authors construct a simple model of democratization that includes individualist and collectivist cultures. They show that countries with a more individualistic culture, despite potentially being less able to overcome collective-action problems, are more likely to adopt democracy faster than countries with a collectivistic culture. Empirically, they show that there is a strong causal effect from individualistic cultures to average polity scores, controlling for other determinants of democracy. To establish causality, the authors use (alternatively or together) two instrumental variables: a measure of genetic distance between countries (as a proxy for vertical, parent-to-child cultural transmission) and a measure of historical pathogen prevalence (this should have pushed communities to adopt more collectivist values emphasizing tradition and less openness to foreigners). The idea that individualism and collectivism can affect the functioning of democracy is plausible; in a companion paper, however, the authors also show that individualism is crucial for economic development. Given the possibility that the instrumental variables don't satisfy the

\footnotetext{
54 Political culture is made up of cognitive, affective, and evaluative orientations toward the political system. They identify three types of political cultures: (1) parochial, in which no clear differentiation of specific political roles and expectations exists among actors, i.e., "political specialization is minimal"; (2) subject, in which institutional and role differentiation exists in political life, but toward which the citizen stands in largely passive relations; and (3) participant, in which the relationship between specialized institutions and citizen opinion and activity is interactive. They summarize this general schema as follows: "A participant is assumed to be aware of and informed about the political system in both its governmental and political aspects. A subject tends to be cognitively oriented primarily to the output side of government: the executive, bureaucracy, and judiciary. The parochial tends to be unaware, or only dimly aware, of the political system in all its aspects."
} 
exclusion restriction, some doubts remain on the causality from culture to democratization. In addition to omitted variables, reverse causality could also be a concern, as people who live in a democratic regime could be more inclined to embrace individualist values.

Cultural variables have been proven to be relevant not only for establishing a democracy but also for its functioning. ${ }^{55}$ Nannicini et al. (2012) show that in localities with a higher level of social capital, ${ }^{56}$ citizens are more likely to hold politicians accountable for the aggregate social welfare of the community. They will punish politicians who pursue vested interests and grab rents for specific groups. In contrast, uncivic agents vote based on their own or group-specific interests and are more tolerant of amoral politicians. Nannicini et al. (2012) convincingly test the prediction of their model by using cross-district variation in the criminal prosecution of Italy's parliament members, who, they find, are much less frequently reelected in districts with higher social capital. These results confirm the intuition by Banfield (1958). In his study of a village in Southern Italy, he argued that the lack of social capital made villagers uninterested in checking up on self-interested politicians. In fact, these checkups constitute a public good, which like any other is undersupplied when social capital is low.

Well-functioning political institutions also need citizens who are interested in and participate in politics, including voting at least occasionally, engaging in time-consuming activities, and staying informed. Alesina and Giuliano (2011b) show that strong family ties are negatively correlated with political participation. Once again, this is consistent with the argument by Banfield (1958).

\subsection{From formal institutions to culture}

\section{The impact of exogenous institutional changes and shocks on culture}

To isolate the effect of formal institutions on culture, one needs to identify institutional changes that are reasonably exogenous to cultural evolution. Empirically, the effect of formal institutions on culture has been isolated in various ways.

One possible source of institutional change for which we have data is the advent and fall of Communism in Central and Eastern Europe. Roland (2004) argues that the culture of these countries has changed little as a result of Communism. He documents that cross-country comparisons of various views as captured by the WVS do not change that much across countries as a result of Communism: specific values and beliefs existed in these countries before the transition, and they hardly changed afterward. They encompassed a more authoritarian view of government

\footnotetext{
55 Glaeser et al. (2007) argue that human capital is another precondition for democratic institutions to work.

56 They follow Guiso, Sapienza, and Zingales (2010), defining social capital as civic capital, "those persistent and shared beliefs and values that help a group overcome the free rider problem in the pursuit of socially valuable activities."
} 
and a preference for more government responsibility over the economy. Moreover, these values and beliefs do not appear to have converged toward those existing in advanced democracies and market economies, be it the EU-15 or the United States. Roland's idea is that institutional evolution in these regions seems to follow a long-run path shaped in large part by a country's long-run history. In contrast, the recent history of communism seems to leave fewer traces than its long-run history.

Shiller et al. (1992) exploited the collapse of the Soviet Union and East Germany to explore the potential impact of socialism on individual attitudes. By using surveys on six countries, they found little evidence of the so-called Homo Sovieticus. ${ }^{57}$

Both studies, though providing an intriguing hypothesis, suffer from several limitations. The sample size is not so large (especially with Shiller); in addition, we think the authors could have better attempted to test for age cohort effects and geographical differences to verify more convincingly whether living under a Communist regime permanently affected attitudes. Indeed, different results emerge when a more stringent identification strategy (Alesina and Fuchs-Schündeln, 2007 ) is adopted. The authors use two vastly exogenous events to the preferences of Germans: separation due to a military defeat (and the border determined by postwar agreements between the Allies) and reunification due to the collapse of the Soviet Union. Taking advantage of the fact that before the separation the inhabitants of East and West Germany were ex ante uniform, ${ }^{58}$ these authors explore, using German opinion surveys after reunification, the effect of 50 years of Communism on Germans' beliefs and preferences, focusing on people's views about the role of the state in the economy and in providing services and social insurance. They find that East Germans after reunification remain more pro-government than West Germans, possibly as a result of indoctrination or more simply because they had gotten used to an intrusive government. ${ }^{59}$ Alesina and Fuchs-Schündeln (2007) show that the convergence of preferences between former East

\footnotetext{
${ }^{57}$ The authors study three former communist countries (Russia, Ukraine, and Eastern Germany) and three advanced capitalist economies, the United States, Japan, and Western Germany. Their sample consists of 2,670 interviews.

58 The authors tested for systematic differences along various dimensions. To test whether the two regions were similar in terms of income, the authors analyzed the average per capita incomes of different German regions, as well as subregions of Prussia, in 1928, 1932, and 1936. The authors found no significant difference. To control for the possibility that Prussians might have had different beliefs, they include a dummy for being under the Prussian empire (part of former Prussia belonged to the Federal Republic of Germany and part to the German Democratic Republic). At the dawn of the 20th century, the areas that became East and West Germany were also quite similar along many economic dimensions, including the percentage of the population working in industry, agriculture, or commerce. In the elections of 1899, finally, around the same number of constituencies in both areas voted primarily in favor of the Social Democrats. If anything, the West was more in favor of state intervention than the East.

${ }^{59}$ Obviously, the authors control for the fact that former East Germans may be more pro-government than former West Germans simply because they are on average poorer.
} 
Germans and West Germans is proceeding relatively quickly and might be complete in two generations. $^{60}$

Overall, the results on the advent and fall of Communism in Central and Eastern Europe appear to be mixed, with earlier studies finding no effect. We believe this may be due to small sample sizes and the inability to control for age-cohort effects and geographical characteristics; Alesina et al. (2007) show more convincingly that living under the Communist regime had strong effects on people's attitudes.

A second set of papers isolates the relevance of formal institutions by looking at countries belonging to different historical empires. Several empirical strategies were employed to isolate the importance of empires.

Becker et al. (2011) focus on the Hapsburg Austrian Empire, known for its well-functioning, well-respected bureaucracy, at least when compared to other empires in Eastern Europe, such as the Ottoman and Russian Empires. This regime created trust in government institutions by developing modern state institutions and enforcing the rule of law. To test whether confidence in institutions persists today, the authors compare people living in communities located within 200 kilometers of each other on either side of the Habsburg border, exploiting the geographical discontinuity created in Eastern Europe by the Habsburg Empire. In order to avoid capturing unobserved country heterogeneity, they use country fixed effects to restrict the analysis to variation within individual modern-day countries. ${ }^{61}$ Though they find some effect on various measures of trust toward the government, not all measures of trust show significant differences, so the results are interesting but inconclusive.

Grosjean (2011) examines location pairs within Eastern Europe and shows that the longer a pair was under the same empire historically, the more similar the reported social trust of the locations' citizens today. ${ }^{62}$ Peisakhin (2010) surveyed 1,675 people living in 227 villages located within 25 kilometers of the Habsburg-Russian border that divided Ukraine between 1772 and 1918.

\footnotetext{
${ }^{60}$ Paul Hollander (1999) had a different interpretation for the decline of communism, according to which the causality runs in the opposite direction. He documents a change in beliefs among leaders and political elites, using a case study method, consisting of analyzing the life stories of 22 Soviet and East European Communists, including early defectors, leaders, and functionaries. In particular, he notes a change in the ideology of the elite, "their loss of political will, intertwined with their eroding sense of legitimacy, [...] appears to be the crucial factor in unraveling of the communist systems." It is unclear whether this limited evidence can sustain the book's broader argument. For one thing, the group he examined can hardly be taken as representative of the Soviet elite as a whole.

${ }^{61}$ The Habsburg border cuts through five countries today: Montenegro, Poland, Romania, Serbia, and Ukraine.

62 The data include 21,000 households in 1,050 primarily sampling unit. The relevant empires in her sample are the Ottoman, the Austro-Hungarian, the Russian, and the Prussian.
} 
Relying on information on cultural traits based on answers to survey questions, Peisakhin (2010) documents a wide range of statistically significant cultural differences between the two groups.

An interesting example of how a political shock could shape religious differences is analyzed by Botticini and Eckstein (2005, 2007). The authors link Jewish population dynamics, educational and occupation choices, conversion, and migration to the same episode: the destruction of the Second Temple in the first century. Before the destruction of the temple, the two main groups were the Sadducees, who accepted only the Written Torah and adopted the Hellenistic culture, and the Pharisees, who aimed to expand the study of both the Written Torah and Oral Torah among all Jews and opposed the expansion of Greek language and culture. When the temple was destroyed, the Pharisees became the dominant group. They replaced sacrifices, which could only be performed in the temple, with the study of the Torah in the synagogues, whose main function was to provide religious instruction to children and adults.

The authors show that the norm requiring Jewish fathers to educate their sons determined several major patterns in Jewish history: on the one hand, Jewish farmers who invested in education gained a comparative advantage and the incentive to enter urban skilled occupations during the vast urbanization in the newly developed Muslim empire. This was also at the origin of the voluntary diaspora of the Jews in search of worldwide opportunities in crafts, trade, and money lending. At the same time, the shock also implied a slow process of conversion from Judaism among illiterate Jewish farmers who lived in subsistence economies: according to the authors, between 30\% and 60\% (depending on location) of the Jewish population, decided to leave Judaism and convert to other religions, mainly Christianity. Most Jewish converts to Christianity were uneducated and lowincome.

Overall, an initial shock implied the diffusion of a costly religious norm requiring fathers to educate their sons. This norm, in turn, could not survive in the long run in subsistence farming economies, where literacy did not increase earnings, and could instead survive only in those places in which Jewish people could find occupations in which their earnings rose significantly from literacy. The paper provides an interesting historical reconstruction of how an initial shock affected religious norms and how this change in turn had long-term economic effects.

Wars and economic shocks can also shape values and beliefs. The research into war's effect on attitudes has explored how a recent history of violence could shape norms of fairness. Whitt and Wilson (2007), for example, in looking at how people treat their in-group and their out-group, observe how much money people send in a dictator game to an anonymous but ethnically 
identifiable counterpart. The sample comprises 681 Muslims, Croats, and Serbs in postwar BosniaHerzegovina. The results indicate that a norm of fairness persists, despite preferential in-group treatment and a distinct out-group effect. In a similar vein, Bauer et al. (2011) test the specific prediction that the experience of intergroup conflict shifts individual psychological motivations to favor in-group egalitarianism. The authors administered a series of social-choice tasks, designed to isolate in-group egalitarian motivations from selfish or generalized egalitarian and altruistic motivations, to over a thousand children and adults who were differentially affected by war in both the Republic of Georgia and Sierra Leone. The authors show that exposure to conflict-related violence between the ages of 7 and 20 shifts people's motivations to greater equality for in-group members. Overall, their results suggest that psychological reactions triggered by war during a particular developmental window generate more in-group-oriented egalitarian motivations. Other studies use behavioral games to link war and social motivations; in one, an ultimatum game conducted before, during, and after the Israel-Hezbollah conflict demonstrates that living in a society under an active, ongoing external threat temporarily increases the willingness of senior citizens to punish non-cooperators and reward cooperation (Gneezy and Fessler, 2011). Voors et al. (2012) reveal that in Burundi, people who have experienced war-related violence share more with their neighbors. ${ }^{63}$

Giuliano and Spilimbergo (2014) look at how the experience of macroeconomic shocks when young affects beliefs regarding the role of luck versus effort as a determinant of economic success, as well as preferences for redistribution and political behavior. The authors show that individuals who grew up during a recession tend to support greater government redistribution, believe that luck is more relevant than effort in determining economic success in life, and vote more for left-wing parties. ${ }^{64}$

The authors combine evidence from three data sources. First, they identify the effect of recessions on beliefs, exploiting time and regional variation in macroeconomic conditions using data from the 1972-2010 General Social Survey, which allows them to control for nonlinear time-period, life-cycle, and cohort effects, as well as a host of background variables. Second, they use longitudinal evidence drawn from the National Longitudinal Survey of the High School Class of 1972 (NLS72) to corroborate the age-period-cohort specification and look at heterogeneous effects of experiencing

\footnotetext{
63 Acemoglu et al. (2011) study the effect of the Napoleonic conquest on the institutions of the regions that fell under French domination. This paper, however, does not investigate cultural effects.

${ }^{64}$ Malmendier and Nagel (2011) show that recessions make people more risk-averse and lower their propensity to invest in the stock market.
} 
a recession during early adulthood. Finally, they confirm their findings with a sample of 37 countries whose citizens experienced macroeconomic disasters at different points in history, using data from the WVS.

\section{Experimental evidence}

An alternative approach for identifying the effect of institutions on culture is to observe in laboratory experiments how people behave in different institutional settings. In their seminal work, Henrich et al. (2001) study 15 small, preindustrial societies and show that group-level differences in economic organization and the degree of market integration explain much of the behavioral variation across societies: the higher the degree of market integration and the higher the payoffs of cooperation, the greater the level of cooperation in experimental games. Gneezy, Leibbrandt, and List (2012) look at the evolution of trust, cooperation, and coordination in different Brazilian fishing villages. In villages located by the sea, fishermen work in teams; in villages located around a nearby lake, fishing is an individual activity. Fishermen from both societies took part in seven experiments: a trust game, an ultimatum game, a donation game, a lottery game, a public-goods game, a coordination game, and a competition game. The authors find that the sea fishermen trust and cooperate more and are more able to coordinate group actions than their lake fishermen counterparts.

Herrmann et al. (2008) conducted large-scale cooperation games with and without punishment opportunities in 16 cities (which should be a proxy for a different institutional environment). They find that cooperation and antisocial punishment is highest in Boston and Melbourne and lowest in Athens and Muscat. The order is highly correlated with the rule of law and the transparency of institutions in the corresponding country.

All these papers are consistent with the argument that people internalize social norms that emerge from specific circumstances (war, economic shocks) or specific needs (the fishermen in Brazil) and support the idea that differences in the institutional environment play a decisive role in the prevalence of various types of norms.

A more sophisticated class of experiments involves manipulation of formal rules. Compared to the simpler approach of observing people in a different institutional environment, this approach allows for a controlled experiment to estimate how people change their culture depending on exogenous variation in the rules of the games.

A set of experiments on the impact of democratic rules on behavior (Tyran and Feld, 2006; Ertan, Page, and Putterman, 2010; and Sutter et al., 2010) find that punishment and rewards in 
public-goods games have a greater impact on behavior when they are allowed democratically. The concern with these sets of experiments is selection: even if groups are formed randomly, groups choosing a particular policy could still have different preferences than those that don't choose that policy. Dal Bo et al. (2010) solve the problem of selection by studying whether the effect of a policy depends on whether it is imposed endogenously or exogenously. The authors design a laboratory experiment to study how democracy affects cooperation. In particular, they are able to distinguish how cooperation changes when a policy is imposed endogenously through a democratic process or imposed exogenously. In the study, subjects participate in several prisoners' dilemma games and may choose, by simple majority, to establish a policy that could encourage cooperation by imposing fines on non-cooperators. In some cases the experimental software randomly overrides the subjects' votes and imposes the policy. Before proceeding to play again with either the original or the modified payoffs, the subjects are informed of whether payoffs are modified and whether it was decided by their vote or by the computer. The authors show that the effect of the policy on the percentage of cooperative actions is $40 \%$ greater when the policy is democratically chosen by the subjects than when it's imposed by the computer.

The drawback of the experimental literature is its external validity, as formal rules in experimental games differ from real-world institutions. This concern is common to all experimental literature, but in some cases-for example, testing the existence of complex social interactions in a small group as a proxy for large real-world societies-the problem of external validity is more difficult to overcome. Dal Bo et al. (2010), consistent with this view, ague that, though the extent to which their results apply to state- or national-level democratic processes is unclear, the results may still be useful in understanding democratic processes in small settings, such as villages in low-income countries, or in understanding the effects of worker participation in firms, and the design of procedures in small groups such as academic departments. (For example, the effects of a policy to monitor schoolteachers' attendance that arise when the policy is randomly allocated across schools may be quite different from the effects of a policy chosen in part by teachers in each school.)

Other research in a non-experimental setting supports the notion that democratic institutions may affect cooperative behavior. Bardhan (2000) finds that farmers are less likely to violate irrigation rules when they themselves have crafted those rules. Frey (1998) finds that Swiss cantons with greater democratic participation face lower tax evasion. Levine and Tyson (1990), Bonin, Jones, and Putterman (1993), and Black and Lynch (2001) find that worker participation in workplace decisions may boost productivity. Several issues with the above-mentioned evidence 
could arise: societies or groups with democratic institutions may differ from societies or groups without those institutions (Swiss cantons with great democratic participation may differ from cantons with low democratic participation because of other differences, for example civic capital). Second, democratic societies or groups may choose different institutions or policies. Finally, there is a selection into policy, since democratic choice allows groups with different characteristics to choose different policies. Experiments allow researchers to circumvent these threats to identification.

\section{Culture and the market}

Bowles (1998) emphasizes the role of the fundamental economic institution, the market, in the formation of preferences/culture. He develops a model in which the basic intuition is that the distribution of cultural traits in a population is determined as the equilibrium of a system whose exogenous elements are subject to the long-term influence of markets and other economic institutions. Economic institutions affect the evolution of preferences by changing these exogenous determinants of the cultural equilibrium.

Bowles' main conclusion is that economic institutions (i.e., the market) may affect preferences through five different channels: their direct influence on situational construal, forms of rewards, the evolution of norms, task-related learning, and their indirect effects on cultural transmission itself. He concludes that "the production and distribution of goods and services in any society is organized by a set of rules, among which are allocation by fiat in states, firms, and other organizations. ... Particular combinations of these rules give entire societies modifiers such as "capitalist," "traditional," "communist." ... One risks banality, not controversy, in suggesting that these allocation rules therefore influence the process of human development, affecting personality, habits, tastes, identities, and values." Further, he states, "the argument that economic institutions influence motivations and values is plausible, and the amount of evidence consistent with the hypothesis is impressive." In particular, several ethnographic and historical studies recount the impact of modern economic institutions on traditional or indigenous cultures. (See Bowles, 1998, for a review of these studies.) He also argues that the rise of feminist values, the reduction in family size, and the transformation of sexual practices coincided with the extension of women's labor-force participation.

This last point has been more formally developed by Fernandez (2013) and Fogli and Veldkamp (2011), who show how women learn about the long-run payoffs from working by observing nearby employed women. Culture would then quickly evolve over time as a result of this process: when few women participate in the market, information is scarce and participation rises 
slowly. As information accumulates, the effect of maternal employment becomes less uncertain and female labor-force participation increases.

\section{Regulation and culture}

Regulations are institutional characteristics that could shape differences in values. Gruber and Hungerman (2008) study the effect of changes in regulation (shopping hours) on religious practices (church attendance). The authors identify a policy-driven change in the opportunity cost of religious participation based on changes in "blue laws," state laws that prohibit retail activity on Sunday. Many states have repealed these laws in recent years, raising the opportunity cost of religious participation. The authors show that when a state repeals its blue laws, religious attendance falls, as do church donations and spending. Repealing the laws may not be an exogenous event; in addition, declining levels of religiosity may have led to the laws being repealed, rather than the other way around. The authors address these concerns by including several controls for a state's socioeconomic circumstances. In addition, they do a placebo exercise by including a dummy for the two years before the blue-law repeal. The dummy is insignificant. As a further test, the authors note that if omitted factors drive down religious participation, they are also likely to reduce participation in other group activities. The authors find that whereas blue-law repeals do lower church-group membership, they exert no effect on the probability of being a member of any other group.

Di Tella et al. (2007) conduct an experiment among squatters in Buenos Aires who randomly received land titles. The authors show that receiving land titles changes a wide range of beliefs and values (such as individualism, the role of merit, and trust). Another interesting example is a study done by Kohn et al. (1990) over a period of three decades. The authors, using evidence from Japan, the United States, and Poland based on a sample of male employees, show that one's position in an occupation hierarchy strongly affects the person's valuation of self-direction and independence in their children, intellectual flexibility, and personal self-directness. These results are not driven by selection. In a series of related studies, longitudinal data provide instruments to address the question of reciprocal causation, leading to evidence of a substantial casual effect of occupationally determined values on other people's values, orientation, and cognitive functioning.

In summary, the arguments about the effects of institutions on culture rely on experimental evidence and on historical natural experiments where institutions vary in locations with common geographical, cultural, and other socioeconomic characteristics. Both methods are convincing, with some caveats. Experimental evidence might be difficult to generalize outside the laboratory; or at least similar conclusions can be drawn for specific real-world situations (see the comment on Dal Bo 
et al., 2010, above). If one wants to play devil's advocate, even the identification of the natural experiment as a change in institution could be debatable, as institutions generally reflect the cultural attitudes of the institution builders (as discussed for Fisher, 1989).

In the next section, we discuss a more promising line of research that doesn't try to identify a single cause but rather looks at the interactions between culture and institutions.

\subsection{The interaction between culture and formal institutions}

The most promising approach, both theoretically and empirically, to studying the interaction between culture and institutions recognizes and embraces a two-way effect to explain economic development and other types of economic outcomes, rather than stressing causality in one direction or the other. Recent contributions have looked at the coevolution of culture and institutions, leading to multiple equilibria characterized by a combination of some types of culture and some types of formal institutions. The general idea underlying this approach is that a country (or a region or an ethnic group, for example) shares certain cultural values, which leads to the choice of certain institutions. In turn, certain institutions lead to the survival (and transmission across generations) of certain cultural values.

Below we describe various papers that explore this interaction. What they have in common is their analysis of the two-way relationship. This interdependence generates, in all models, multiple stable equilibria, with different sets of self-reinforcing institutions and cultural norms. This coevolutionary structure has been applied to several cultural traits: cooperation, trust, family ties, individualism, and fairness.

The coevolution of cooperation and formal institutions

Tabellini (2008b) provides a formal model of the interplay between culture and legal institutions, which enforce contracts. ${ }^{65}$ The model has three ingredients: (1) two potential cultural traits (generalized versus limited morality), one of which values cooperation more than the other: cooperation between the immediate family and the clan (limited morality) is relatively easy to sustain; cooperation among distant (i.e., less connected) players (generalized morality) is more difficult to sustain. People face moral costs if they don't cooperate in a prisoner's dilemma game, even when the game is played only once. These costs decrease as the distance between players grows; (2) a mechanism of vertical cultural transmission of values, with parents exerting costly effort to instill

\footnotetext{
${ }^{65}$ Tabellini (2008b) builds on Dixit (2004) and also on Bisin and Verdier (2001) for the model of intergenerational transmission of values.
} 
cooperation; (3) formal institutions (which enforce cooperation) endogenized through majority voting.

The larger the share of cooperative players, the more it is in everybody's interest to cooperate and the more parents will teach children to cooperate. This kind of complementarity gives rise to the possibility of multiple equilibria, one with limited morality and one with generalized morality. Well-functioning legal institutions may increase both the cost of noncooperation and the number of cooperative players. This effect, combined with the complementarity described above, may switch a society from an equilibrium with limited morality to one with generalized morality. On the other hand, with generalized morality the need for institutional interventions to punish cheating is less frequent, leading to better-functioning institutions and reduced caseloads. Good institutions and generalized morality are therefore self-reinforcing. Good institutions foster generalized morality, reducing legal caseloads and court crowding. Poor institutions do the opposite, decreasing morality and making people more litigious, cluttering the legal system. Tabellini's paper also implies that globalization - in which economic interactions are more and more common amongst distant players-makes the need for good legal enforcement and generalized morality even more important. ${ }^{66}$

Acemoglu and Jackson (2012) disagree in part, arguing that norms of cooperation may evolve quickly and sometimes respond to leaders or institutional changes. The motivation for their paper comes from the historical observational differences in cultural, social, and political behavior between Northern and Southern Italy. Whereas the literature has emphasized that "amoral familism" and lack of "generalized trust" are at the origin of the "inability of the villagers to act together for their common good" (Banfield, 1958), these differences are not set in stone. The authors refer to Locke (2002), who provides examples from the south of Italy and northeastern Brazil, where starting from conditions similar to those emphasized by Banfield, trust and cooperation emerged at least in part as a result of "leadership" and certain specific policies. In addition to leadership by prominent agents, social norms could also be affected by institutions or policies that encourage more cooperative behavior. Whether the examples of leadership leading quickly to generalized trust are the exception or the rule remains to be seen. Guiso, Sapienza, and Zingales (2013) provide convincing empirical evidence of the long-term persistence (over several centuries) of cooperation

\footnotetext{
${ }^{66}$ Jackson (2013) extends the Tabellini model to a case of joint production. For a related model, in which law and morality can be substituted, see Bonhet, Fey, and Huck (2001).
} 
and trust in Italy, spanning numerous political regimes, leading to the different functioning of modern political institutions. ${ }^{67}$

The interaction of culture and institutions has also been studied using cultural-evolution models (see Bowles and Gintis, 2010). The authors define culture as the set of preferences and beliefs acquired by means other than genetic transmission. What distinguishes humans from animals is the way we acquire information. For most animals, genetic transmission and individual learning are the only means for acquiring information. Humans, by contrast, also acquire information through social learning. Social learning, or cultural transmission, as opposed to individual learning, takes the forms of vertical (parents to children), horizontal (peer to peer), and oblique (non-parental elder to younger) transfer of information.

The authors use institutions to explain the evolution of altruistic behavior over time. In particular, their idea is that group competition and culturally transmitted group differences in institutional structures are crucial in explaining the evolution of cooperative behavior among humans. Group differences in institutional structures persist over long periods due to the nature of institutions as "conventions," common practices adhered to by virtually all group members because the relevant behaviors are mutual best responses, conditioning on the expectation of similar behaviors by most others.

The conventional nature of institutions accounts for their long-term persistence and also their occasional rapid change under the influence of shocks. In their model, when new members of the population mature or immigrate, they adhere to the existing institutions, not because of conformist learning but because this is a best response, as long as most others do the same. In that sense, institutions are group-level characteristics; successful institutions, like the European national states, produce many replicas, while unsuccessful institutions disappear. Institutions may replicate when a successful group grows or when a group with unsuccessful institutions succumbs to a military, ecological, or other challenge. The novelty of their evolutionary approach is that institutions, as individual characteristics, are subject to selection. For example, food sharing beyond the family, which reduces within-group differences in material well-being, attenuates within-group selective pressures. Groups adopting institutions such as food sharing help proliferate group-beneficial individual traits, including altruism.

The coevolution of culture and regulation

${ }^{67}$ Their work confirms the hypothesis of Putnam et al. (1993) that we discussed in the introduction. 
Whereas Tabellini (2008b) has only a theoretical framework to explain the coevolution of culture and institutions, three recent papers have also contained an empirical study of this interaction. Aghion et al. (2010) look at the interaction between generalized trust and regulation. Aghion el al. (2011) examine contemporary labor markets and identify a negative interaction between the existence of cooperative labor relations and the severity of a state-mandated minimum wage. Alesina et al. (forthcoming) look at the positive relationship between the strength of family ties and the strength of labor-market regulation.

Aghion et al. (2010) present a model and provide empirical evidence to explain the coevolution of trust and regulation. In their framework, trust is defined as beliefs resulting from family decisions about civicness. The model, similarly to Tabellini (2008), has three elements: (1) Two cultural traits: being civic or being uncivic. People need to make two decisions, whether to become civic and whether to become entrepreneurs or choose some form of routine production (such as state production). Those who become uncivic impose a negative externality on others when they become entrepreneurs (for example pollute), those who become civic do not. (2) A mechanism of cultural vertical transmission according to which children are thought to become civic or uncivic by their parents. (3) A political mechanism (such as voting) that allows the community to regulate entry into entrepreneurial activity when the expected negative externalities are large. Regulation constrains choices, hence negative externalities, but is at the same time implemented by government officials, who demand bribes when they are un-civic.

When people expect to live in a civic community, they expect low levels of regulation and corruption, and so become civic. When they expect to live in an uncivic community, they expect high levels of regulation and corruption, and do not become civic. The model has two equilibria: one with a large share of civic individuals and no regulation, and another in which a large share of uncivic individuals support heavy regulation.

In the empirical part, the authors test several predictions of the model; relevant for our purposes are a negative correlation not only between trust and regulation but also between trust and demand for regulation. The authors take the evidence on the demand for regulation as consistent with the link running from distrust to regulation. To show that the other effect is also present, from regulation to trust, they examine the experiment of transition from socialism, which was a radical reduction in government control in low-trust societies. Their model predicts that such a reduction should lead to, among other things, an increase in the demand for government control at a given level of trust and a reduction in trust in the short run. Their results hold using three different 
datasets: the WVS, the International Social Survey Program (ISSP), and the Life in Transition Survey (LITS). ${ }^{68}$ The authors find consistent evidence that distrust leads to support for government regulation. Although the exercise uses within-country variation-the authors can therefore include country fixed effects - the drawback of their empirical strategy is that certain omitted variables could drive both the demand for regulation and distrust. For the evidence regarding transition economies, the drawback is that the end of Communism could have caused other changes in addition to the liberalization of entrepreneurial activity that drives the change in trust. ${ }^{69}$

Aghion, Algan, and Cahuc (2011) also have a model of interaction between regulations and culture. The sequence of decisions in the model is as follows: the trade union decides whether to invest in the quality of labor relations; people vote to elect a government that sets a minimum wage; workers decide whether to join the trade union; wages are set by employers for nonunionized workers and by wage negotiation for unionized workers.

In this framework, higher-minimum-wage regulation reduces the benefits to workers of trying to cooperate with firms. Therefore, more stringent minimum-wage regulations crowd out cooperation between firms and workers. In turn, less cooperative firm-worker relationships increase the demand for minimum-wage regulation. This interdependence explains the observed negative relationship between the minimum wage and cooperative labor relations.

To identify the effect of attitudes on institutions, the authors use historical data on state attitudes toward labor-market relations from Crouch (1993), who classifies states in three categories regarding labor-market relations: (1) Four states that were hostile to the development of unions and consequently prone to directly regulating labor markets and settling disputes through centralized decisions. This group consists of the main Catholic countries in Europe, namely France, Italy, Spain,

\footnotetext{
${ }^{68}$ The WVS poses general questions concerning attitudes toward competition and state intervention. The ISSP contains specific questions on the regulation of wages and prices. The LITS provides evidence on 28 post-Communist countries in Europe and Central Asia, and it has questions on preferences for market versus planned economies.

${ }^{69}$ Similar conclusions have been reached by Pinotti (2012), Carlin, Dorobantu, and Viswanathan (2009), and Francois and Ypersele (2009). Pinotti (2012), looking at the correlation between trust and regulation, shows that variations in entry regulations around the world mostly reflect demand pressures from people at large, as captured by differences in trust. His contribution, when compared to Algan et al. (2010), is to address the implications of these findings for the cross-country pattern of trust, regulation, and market failures. He shows that, keeping constant the trust-driven component of demand for government intervention across countries, regulation is no longer associated with worse economic outcomes. Carlin et al. (2009) look at how trust evolves in the market, what the optimal level of government regulation is, and how this intervention affects trust and economic growth. They show that when the value of social capital is high, government regulation and trustfulness are substitutes. In this case, government intervention decreases economic growth. On the other hand, when the value of social capital is low, regulation and trust may be complements. Francois and Ypersele (2009), using data from the General Social Survey, found a strong positive relationship between individual trust and the competitiveness of the sector in which an individual works. Their idea is that competition mitigates incentives for free-riding by imposing a costly shutdown on poor-performing firms, making employees more trustworthy, which increases trust.
} 
and Portugal. In these countries, the central government needed to establish its authority over the Catholic Church and to confront all forms of organized interests, including worker organizations. The second category comprises seven countries where the state was neutral regarding labor organizations: Belgium, Denmark, Norway, Sweden, Finland, the United Kingdom, and Ireland. The third category comprises countries where the state that encouraged union involvement in the regulation of labor markets: Austria, Germany, the Netherlands, and Switzerland.

The dependent variable of Aghion et al.'s (2011) specification is the quality of labor relations in OECD countries in 2000 as a function of the attitudes of the state toward unions in the 19th century. The authors find that attitudes affected institutions even after controlling for the unemployment rate and other labor-market institutions (including replacement rate, benefit duration, employment protection, and tax wedge). To establish the opposite channel of the effect of institutions on attitudes, the authors look at the impact of union density in the home country in 1950 on the current unionization attitudes of first- and second-generation immigrants in the United States born after 1950.

Alesina et al. (2013) study the interaction between family ties and the regulation of labor markets. The model has three different components: (1) a difference in cultural values, specifically in the strength of family ties; (2) a mechanism of vertical cultural transmission, in which people choose the strength of family ties to transmit to their children; (3) a majority-vote political mechanism, which allows people to choose the degree of labor-market regulation.

Flexible labor markets require that people move geographically to maximize their opportunities, find the best match with a firm, and get the best-paying job. This model is efficient when mobility is painless. However, in societies with strong family ties, staying close to family is important, and the mobility required by a free labor market can be painful. With unregulated labor markets, local firms would have a monopolistic power over immobile workers, who would demand labor regulation to counteract this power. This can lead to two different equilibria. One is laissezfaire, with high mobility and unregulated labor markets; this occurs when family ties are weak. When family ties are strong, the other equilibrium evinces labor-market rigidity with minimum-wage and firing restrictions. Given the cultural value placed on family ties, labor-market regulation is preferable to laissez-faire; even though laissez-faire produces higher income per capita, it rarefies family relations. If family ties are sufficiently strong, this relaxation of family relationships can reduce individual utility so much that welfare can be higher with a regulated labor market. The 
authors show how preferences for labor-market institutions are strongly associated with family values, even within countries.

The findings imply a two-way effect between family ties and labor-market regulation. An inherited culture of strong family ties leads to a preference for labor-market rigidity; the latter, in turn, makes it optimal to teach and adopt strong family ties. In fact, a regulated market creates unemployment and lower wages, and the family provides the necessary social insurance. In other words, the benefits of a strong family enjoying the pleasures of living together necessitate an inefficient institution: labor-market regulations with firing costs and binding minimum wages. Regulated labor markets survive despite their obvious economic costs. Incidentally, this explains why in large parts of Europe where family ties are stronger, labor-market deregulation is one of the most difficult reforms to implement. In Northern European countries, a "flex security" system has proven successful: unemployment is lower and participation in the labor force higher than in Southern Europe. In general, Southern European countries rely much more on the family than Northern European ones to provide social insurance for the unemployed.

In their empirical section, the authors also show that culture is more primitive than institutions by looking at the family values that European descendants have inherited from forebears who migrated to the United States before 1940. They found a strong effect of culture in the determination of labor-market institutions.

The four studies have in common a similar theoretical building block, consisting of differences in the original cultural values, a mechanism of vertical transmission, and a political mechanism for choosing the type of regulation. All the models provide a rationale for multiple equilibria in institutions and cultural values; countries with heterogeneous beliefs can end up in different equilibria; but also, as in Algan et al. (2011), countries starting with the same beliefs in cooperation can diverge and end up in different equilibria, depending on historical idiosyncracies.

Two of the papers (Aghion et al., 2011; Alesina et al., 2013) empirically adopt an identification strategy in which cultural traits are measured in the past as a result of cultural transmission across generations. These past cultural values are then used as main dependent variables for institutions that were created much more recently, thus limiting the issue of reverse causality. Of course, the problem of omitted variables is not solved completely using this approach: a common factor could have caused both persistence in specific cultural traits and development of specific institutions. Aghion et al. (2010) use the end of Communism in Eastern Europe as a natural experiment, but even in this case concerns remain that Communism could have changed some other 
variables that also could have influenced institutions and cultural variables. Despite these limitations, we believe the papers provide sufficient evidence of a feedback effect between culture and institutions.

\section{The culture of work and the redistributive state}

Models with multiplicity of equilibria have also been used to explain the relationship between the culture of work and the redistributive state. ${ }^{70}$ Alesina and Angeletos (2005) highlight the interaction between culture and institutions regarding fairness and redistribution. They develop a model in which income could derive from ability or luck. Voters, in addition to caring about their own income, dislike the notion of inequality due to luck rather than to effort and ability. Multiple equilibria can occur. In one equilibrium, income taxes are high, effort low, the share of individual income due to luck is high, and desired taxes are high, since luck-generated inequality is viewed negatively by voters. In the other equilibrium, taxes are low, effort is high, the fraction of income explained by luck is low, and desired taxes are relatively low. ${ }^{71}$ The motivation was to capture a U.S. versus Europe difference along the lines suggested informally by Alesina, Glaeser, and Sacerdote (2001) and Alesina and Glaeser (2004). ${ }^{72}$ The feedback here is from cultural values (views about poverty) to choice of certain redistributive policies, which reinforce cultural values. Extensive literature based on answers to surveys (see the review by Alesina and Giuliano, 2011a) shows that people who believe that the poor are unfortunate are much more likely to support redistributive policies. $^{73}$

Alesina, Cozzi, and Mantovan (2012) develop these ideas by tracing the evolution over time of ideas of fairness, measured inequality, and preferences for redistribution. They show that longlasting differences in welfare policies result from initial cultural differences about what is and isn't fair about the initial level of inequality. Imagine a society where "at the beginning" wealth inequality was all due to birth, nobility, and the like. Compare it to another society where initial wealth

\footnotetext{
${ }^{70}$ In Piketty (1995), multiple equilibria in beliefs and redistributive policies can originate from the heterogeneity in initial beliefs and how hard it is for people to learn the true costs and benefits of redistribution.

${ }^{71}$ Benabou and Tirole (2006) present a different model that leads to similar conclusions, though based on different behavioral assumptions.

${ }^{72}$ Using happiness data, Alesina, Di Tella, and MacCulloch (2004) show that Americans are less sensitive to inequality.

${ }^{73}$ In the United States, race is important in explaining redistribution. Lee and Roemer (2006) identify two mechanisms through which racism among American voters decreases the degree of redistribution. The first, which has also been suggested by other authors (Alesina et al., 2001; Luttmer, 2001), suggests that voter racism decreases the degree of redistribution due to an anti-solidarity effect: voters oppose government transfer payments to minorities whom they view as undeserving. The second mechanism is that some voters who desire redistribution nevertheless vote for the antiredistributive party (the Republicans) because the party's position on race issues is more consonant with their own. They classify this effect as the "policy bundle effect."
} 
distribution was the result of effort, entrepreneurship, and so on. We can think of the former as Europe, where hundreds of years of feudal instructions created deeply rooted class divisions based on birth. We can think of the latter as the United States, where the initial distribution of wealth was much more the result of successes and failures of entrepreneurs, and of new waves of immigrants. The United States never had feudal institutions, and wealth inequality was accepted as fairer than in Europe. Precisely for this reason, the absence of preindustrial feudal institutions in the United States led Marx and Engels to doubt that communist ideology would succeed there. ${ }^{74}$

Alesina, Cozzi, and Mantovan (2012) show that these different initial conditions at the birth of capitalism, due to different preindustrial institutions, led to long-lasting cultural differences regarding the perception of poverty, the need for extensive government intervention, and the (lack of) respect for the wealthy. These early differences in cultural values still strongly influence policy choices today. These beliefs have become self-sustaining: the more wealth is redistributed via government intervention, the less some people see it as fair, because it is not the market but rather politicians, special interests, and various pressure groups that determine where public money goes.

In this set of models, the multiplicity of equilibria and the long-term persistence come from an initial heterogeneity in beliefs. In addition, shocks may lead to rapid changes in attitudes. For instance, the cultural revolution of the 1960s (this is not the place to discuss its origins) generated a more favorable attitude toward redistribution, even in the United States. And, the recent financial crisis, which exposed enormous wealth accumulated in the financial sector, may have created an antimarket cultural shift, with the associated rhetoric of the "top 1 percent."

\section{Individualism and institutions}

Gorodnichenko et al. (2013a) test empirically whether individualism causally affects institutions or vice versa. To test first for a causal effect of individualism on institutions, the authors regress measures of institutions at the country level (given by the protection against expropriation risk, also used in Acemoglu et al., 2001), on the measure of individualism taken by Hofstede (2001) and a series of controls for geography, a dummy for continents, and the percentages of population practicing major religions. Individualism is instrumented using a specific measure of genetic markers, given by Mahalanobis distance between the frequency of blood types in a given country and the frequency of blood types in the United States (the most individualistic country in their sample). Here's the idea behind the instrument: to the extent that culture is transmitted mainly from parents

\footnotetext{
${ }^{74}$ See also Sombart (1976).
} 
to children, so are genes. ${ }^{75}$ In addition, when the authors use genetic distance as an instrumental variable, they don't postulate a causal relationship between genes and cultural attributes such as individualism; they simply exploit the correlation between genetic distance and cultural differences across populations, as both genes and culture are transmitted from parents to offspring. Since the measure of genetic distance uses only neutral genetic markers, which have no direct effect on fitness and thus on cultural outcomes, this variable is likely to satisfy the exclusion restriction. To test for causality in the other direction-institutions on individualism-the authors regress measures of individualism at the country level on measures of institutions (the variables described above). Institutions are instrumented with settler mortality (see Acemoglu et al., 2001).

The authors find that individualism exerts a positive, significant effect on institutions, thus implying a flow of causality from individualistic culture to institutions. However, the effect of institutions on culture is not robust across specifications. The authors conclude that the effect of institutions on culture might be less robust than the other way round, with the caveat that they drew their conclusions from a small sample-only 35 observations.

\section{Culture, institutions, and economic outcomes}

The feedback effect between culture and institutions is particularly relevant in explaining economic growth and other economic outcomes, such as participation in the labor market or the provision of public goods.

Doepke and Zilibotti (2008) model the interaction between economic opportunities and preference formation through parental investments (concerning the rate of time preferences and the taste for leisure) around the Industrial Revolution. The idea is simple but powerful. Before the Industrial Revolution (when capital markets were imperfect), the rich could rely on rental income and therefore develop a taste for leisure. The middle class, working instead in occupations requiring effort, skill, and experience, had to invest in two cultural values: patience (low discount factor) and work ethic. The specific attitudes of the middle class, in turn, became the key determinant of economic success once the Industrial Revolution had transformed England. A limitation of the paper is why this pattern happened only in England and not in other countries.

Tabellini (2008a and 2010) explores the interconnection between institutions and generalized morality to explain differences in development throughout Europe. He studies regions in eight European countries in which differing levels of generalized morality resulted from different historical experiences. Comparing regions within today's countries, the author shows that differing

\footnotetext{
${ }^{75}$ For a critical view of the use of genetic distance in economics, see Giuliano, Spilimbergo, and Tonon (2014).
} 
levels of generalized morality are persistent, are correlated with good functioning of current institutions, and are favorable to economic development. Current morality is related to the level of human capital accumulated in the 18th century, and to the level of democratization and independence the regions gained from absolute monarchs. Thus institutions in the distant past led to the development of a culture of generalized morality, which in turn helped foster well-functioning current institutions.

This argument is related to the work by Putnam et al. (1993) and Guiso, Sapienza, and Zingales (2013) on the development of social capital in free medieval cities in Italy. In this case as well, ancient institutions led to long-lasting cultural changes, which affected the functioning of current institutions, as we discussed in the introduction.

Michalopoulos and Papaioannou $(2013,2014)$ study the relative importance of culture and institutions in Africa. In their first paper, the authors look at the spatial distribution of ethnicities before colonization in Africa and show that historical local institutions, ${ }^{76}$ - in particular, measures of precolonial political centralization and not national institutions-can explain within-ethnicity differences in economic performance, using as a proxy satellite images of light density at night. To rule out the possibility that precolonial political centralization is capturing some other omitted variable, the authors control for geographical, ecological, and natural-resource endowment at the ethnic level. In addition, they show that the results do not depend on observable ethnic differences in culture, occupational specialization, and the structure of economic activity before colonization.

In their second paper, the same authors reached a more nuanced conclusion. They claim that one cannot disentangle institutional features of a society from its long-term cultural traits, which are transmitted intergenerationally within ethnic groups. Those deeper ethnic and cultural traits, rather than national institutions, affect economic outcomes in Africa. For their main identification strategy, the authors exploit the fact that political boundaries on the eve of African independence partitioned more than 200 ethnic groups across adjacent countries. They then compare the economic performance of the same ethnic groups, who were now partitioned in different countries and thus subject to different national institutions. With this identification strategy, they can hold constant geographical and ethnicity-specific cultural traits. They found that cross-border differences in national institutions do not systematically translate into differences in economic performance within partitioned ethnicities - in particular, the positive correlation between national institutions and development disappears with the inclusion of ethnicity fixed effects.

\footnotetext{
${ }^{76}$ For the relevance of historical local institutions, see also Gennaioli and Rainer (1997).
} 
The authors highlight two additional results: first, they show that conditioning on the degree of precolonial centralization and the dependence on agriculture and pastoralism substantially weakens the cross-sectional coefficient on the national institutions proxy. This finding is consistent with studies of the African historiography, downplaying the role of national institutional structures and stressing instead the key role of ethnicity-specific traits related to the role of chiefs, culture, and precolonial organization. Second, they find evidence of substantial heterogeneity-in particular, that national institutions correlate with subnational development, but only when both partitions are close to the respective capital cities. They claim that this is consistent with insights from the African historiography, stressing the inability of states to broadcast power in regions far from the capital. ${ }^{77}$

Engerman and Sokoloff (1997) give a different interpretation of the role of culture and institutions in the determination of development: both represent an indirect mechanism through which geography affects economic outcomes. In their work, different factor endowments-in particular, soil suitability for growing sugar, coffee, rice, and in general crops characterized by high market value and economies of scale-helped foster the creation of a small elite, the diffusion of slavery, and the implementation of policies and institutions that perpetuated such inequality, lowering incentives for investment and innovation. This was in contrast to societies that were based on the cultivation of small-scale crops (grain and livestock), which had a more equitable distribution of wealth and better long-term economic performance.

Giavazzi et al. (2013) look at the relative importance of culture and institutions in determining three labor-market outcomes: the employment rate of women, average hours worked, and the employment rate of the young. The authors find that culture matters in two of the three outcomes; however, policies and other institutional characteristics also matter when one considers their endogeneity. Attitudes toward women's role in the family and attitudes toward leisure are statistically and economically important determinants of the employment rate of women and average hours worked. The measure of attitudes toward youth independence does not appear to be important in explaining the employment rate of the young. The two significant policy variables affecting the female employment rate and average hours worked are the index of employment protection legislation/tax wedge and benefits. To reach their conclusions, the authors use a Generalized Method of Moments framework that allows them to obtain consistent estimates when culture is endogenous and labor-market outcomes persist over time. They use religious beliefs as

\footnotetext{
77 This result is consistent with models of country formation and geographical and cultural distance from the capital (Alesina and Spolaore, 2004; Alesina and Reich, 2013).
} 
predetermined variables in the GMM framework, and their lagged values as an instrument. They also test the robustness of their analysis using as an instrument the attitudes of second- (or higher-) generation immigrants to the United States who arrived from different countries at different points in time. The basic idea is that the evolution in the attitudes of U.S. immigrants is correlated with that of attitudes in the country of origin, but not with the idiosyncratic component of the error term in the labor-market-outcomes equations.

Padro-Y-Miguel, Qian, and Yo (2013) study the joint interaction of political institutions and social capital in determining the provision of public goods in Chinese villages. ${ }^{78}$ The authors argue that elections in Chinese villages are more effective at choosing politicians who provide more public goods in villages where social capital is higher and generalized trust is high relative to personalized trust. Identification comes from time variation in the introduction of village elections, as the village had no voice in choosing when or whether to hold elections. In particular, with a difference-indifferences strategy, they look at the presence of public goods before and after elections in various villages. The main result is that elections have very little effect in villages with low social capital and a big effect in villages with high social capital. One of their contribution is trying to distinguish kinship trust from generalized trust. As a proxy for kinship trust, they use the presence of ancestral halls, where people go to venerate the dead relatives of their extended family. The authors show that this proxy is inversely related to the smooth functioning of democracy.

The above-mentioned papers all advance the idea that culture and institutions are complementary. A more general approach is provided in Bisin and Verdier (in progress as of this writing): they develop a more general model in which, depending on the economic environment and initial conditions, culture and institutions might complement each other, or might act as substitutes, contrasting each other and limiting their combined ability to promote economic growth. They posit an interesting idea: even when new institutions are introduced to increase economic growth, their effect depends on whether the appropriate cultural trait develops to support the new institution. ${ }^{79}$

\footnotetext{
78 The authors measure social capital with the presence of village temples, considered as a form of voluntary organization. They collect data showing that the presence of temples is correlated with the presence of other voluntary organizations.

${ }^{79}$ In their theoretical work, Bisin and Verdier define institutions as mechanisms through which social choices are delineated and implemented_-a definition similar to Acemoglu's, but much more general. In Acemoglu et al. (2006), political institutions are mechanisms for distributing political power across different socioeconomic groups; in turn, political power determines economic institutions that govern economic activity. In Acemoglu et al. (2003), for example, institutions are represented by an indicator of which political pressure group in a given set has the power to control social choice. Institutional change, then, results from voluntary concessions by the controlling group, possibly under threats of social conflict. Bisin and Verdier depart from the notion that institutions contain political power and control embedded in one single group. Their measure is more general; specifically, institutions are modeled as Pareto weights
} 
More empirical work is needed to convincingly test hypotheses related to the interaction of culture and institutions. The most successful approach should be able to trace the full impact of culture and institutions through time, examining specific channels and mechanisms. Whoever undertakes this work will need to collect and compile new data on the evolution both of cultural traits and of institutions.

\section{Conclusions}

What roles do culture and institutions play in determining the wealth of nations? We have argued here that it would be wrong to claim the causal superiority of either. Culture and institutions interact and evolve in a complementary way, with mutual feedback effects. Thus, the same institutions may function differently in different cultures, but culture may evolve in differing ways depending on the type of institutions. We discussed many examples of this interaction, for different types of institutions (such as political and legal institutions, regulation, and the welfare state) and different cultural traits (including trust, family ties, individualism, and generalized morality). We also discussed in detail definitional issues, which are important both for clarity of models and for measurement.

Though the studies we've reviewed have done much to emphasize the presence of a feedback effect, two major tasks lay ahead.

First, we need to better understand the mechanisms driving the interaction. Most of the studies still tend to examine an event in isolation from other events, except possibly to account for other covariates. However, the joint dynamics of culture and institutions can be much more complex and highly nonlinear. Therefore, linear regression methods tend to be less appropriate than more structural analyses of the data.

Second, we need to better understand channels of causality. Most of the papers we've reviewed try to isolate one direction of causality, by using instrumental variables or by looking at historical exogenous shocks. The existence of complementarities between culture and institutions hinders identification. While much progress has been made in isolating the importance of culture and institutions, we need to do more to fully understand their complementarities and how they jointly affect development. To find empirical answers to these questions, researchers will need to

associated to the different groups in the social-choice problem. Institutional change, therefore, happens more incrementally than revolutions and regime changes. 
assemble a chronology of both cultural change and institutional change and then examine the interrelationships between them.

\section{References}

Acemoglu, D., 2003, “Why Not a Political Coase Theorem?” Journal of Comparative Economics, 31, 620652.

Acemoglu, D., Cantoni, D., Johnson, S., and J.A. Robinson, 2011, “The Consequences of Radical Reforms: The French Revolution,” American Economic Review, 101: 3286-3307.

Acemoglu, D. and M. Jackson, 2012, "History, Expectations, and Leadership in the Evolution of Social Norms," MIT mimeo.

Acemoglu, D., Johson, S. and J. Robinson, 2001, "The Colonial Origins of Comparative Development: An Empirical Investigation," American Economic Review, 91: 1369-1401.

Acemoglu, D., Johnson, S. and J. Robinson, 2006, "Institutions as a Fundamental Cause of LongRun Growth," in Handbook of Economic Growth, Aghion, P. and S. Durlauf, eds., Amsterdam: North-Holland.

Acemoglu, D., Johnson, S., Robinson, J. and P. Yared, 2008, "Income and Democracy," American Economic Review, 98, 808-842.

Acemoglu, D. and J. Robinson, 2006, Economic Origins of Dictatorship and Democracy, Cambridge University Press, Cambridge.

Aghion, P., Algan, Y., and P. Cahuc, 2011, "Civil Society and the State: The Interplay Between Cooperation and Minimum Wage Regulation," Journal of the European Economic Association, 9 (1), 3-42.

Aghion, P., Algan, Y., Cahuc, P., and A. Shleifer, 2010, "Regulation and Distrust," The Quarterly Journal of Economics, 125(3): 1015-1049.

Akerlof, G. and R. Kranton, 2000, "Economics and Identity," The Quarterly Journal of Economics, 115(3), 715-753.

Albanesi, S. and C. Olivetti, 2009, “Gender Roles and Medical Progress,” NBER WP 14873.

Alesina, A. and G.M. Angeletos, 2005, "Fairness and Redistribution," American Economic Review, 95(4), 960-980.

Alesina, A., Algan, Y., Cahuc, P, and P. Giuliano, forthcoming, "Family Values and the Regulation of Labor," Journal of the European Economic Association

Alesina, A., Cozzi, G., and N. Mantovan, 2012, "The Evolution of Ideology, Fairness, and Redistribution," 2012, The Economic Journal, 122 (565), 1244-1261. 
Alesina, A., R. Di Tella, and R. MacCulloch, 2004, "Inequality and Happiness: Are Europeans and Americans Different?" Journal of Public Economics, 2004, 88(9-10), 2009-2042.

Alesina, A. and N. Fuchs-Schündeln, 2007, “Goodbye Lenin (or Not?): The Effect of Communism on People," American Economic Review, 97(4): 1507-1528.

Alesina, A. and P. Giuliano, 2010, “The Power of the Family,” Journal of Economic Growth, 15, 93-125.

Alesina, A. and P. Giuliano, 2011a, "Preferences for Redistribution," Handbook of Social Economics, in J. Behnabib, A. Bisin and M.O. Jackson (eds.).

Alesina, A. and P. Giuliano, 2011b, "Family Ties and Political Participation," Journal of the European Economic Association, 9(5): 817-839.

Alesina, A. and P. Giuliano, 2013, "Family Ties," in Handbook of Economic Growth, P. Aghion and S. Durlauf (eds.), North Holland, Elsevier.

Alesina, A., Giuliano, P., and N. Nunn, 2013, "On the Origins of Gender Roles: Women and the Plough," The Quarterly Journal of Economics, 128 (2): 469-530.

Alesina, A. and E. Glaeser, 2004, Fighting Poverty in the US and Europe: AWorld of Difference, Oxford University Press.

Alesina, A., Glaeser, E., and B. Sacerdote, 2001, “Why Doesn't the United States Have a EuropeanStyle Welfare State?” Brookings Papers on Economic Activity, 2, 187-254.

Alesina, A. and E. La Ferrara, 2000, "Participation in Heterogeneous Communities," Quarterly Journal of Economics, 115, 857-904.

Alesina A. and E. La Ferrara, 2002, "Who Trusts Others?” Journal of Public Economics, 85, 207-234.

Alesina A., Michalopoulos, S., and E. Papaioannou, 2013, “Ethnic Inequality,” NBER WP 18512.

Alesina A. and B. Reich, 2013, "Nation Building,” NBER WP 18839.

Alesina A. and E. Spolaore, 2004, The Size of Nations, MIT Press, Cambridge, Mass.

Algan, Y. and P. Cahuc, 2013, “Trust, Growth, and Well-Being: New Evidence and Policy Implications," in Handbook of Economic Growth, P. Aghion and S. Durlauf (eds.), North Holland, Elsevier.

Almond, G. and S. Verba, 1963, The Civic Culture. Political Attitude and Democracy in Five Nations, Sage Publications New York.

Arrow, K., 1972, “Gifts and Exchanges," Philosophy \& Public Affairs, 1(4), 343-362.

Banfield, E., 1958, The Moral Basis of a Backward Society, Free Press, New York.

Bardhan, P., 2000, "Irrigation and Cooperation: An Empirical Analysis of 48 Irrigation Communities in South India," Economic Development and Cultural Change, 48 (4): 847-865. 
Barr, A., 2004, "Kinship, Familiarity, and Trust: An Experimental Investigation," in Foundation of Human Sociality: Economic Experiments and Ethnographic Evidence from Fifteen Small-Scale Societies, Henrich, J., Boyd, R., Bowles, S., Camerer, C., Fehr, E., and H. Gintis (eds.), Oxford University Press.

Bauer, M., Cassar, A., Chytilova, J., and J. Henrich, 2011, "War's Enduring Effects on the Development of Egalitarian Motivations and In-group Biases," mimeo, CERGE-EI.

Becker, S. O., Boeckh, K., C. Hainz, and L. Woessmann, 2011, “The Empire Is Dead, Long Live the Empire," CAGE WP 40.

Becker, S.O. and L. Woessmann, 2009, "Was Weber Wrong? A Human-Capital Theory of Protestant Economic History," Quarterly Journal of Economics, 124 (2), 531-596.

Benabou, R., 2008, "Ideology," Journal of the European Economic Association, 6(2-3), 321-352.

Benabou, R. and E. Ok (2001), "Social Mobility and the Demand for Redistribution: The POUM Hypothesis," The Quarterly Journal of Economics, 116, 447-487.

Benabou, R. and J. Tirole, 2006, "Beliefs in a Just World and Redistributive Politics," The Quarterly Journal of Economics, 121(2), 699-746.

Bertrand, M. and A. Schoar, 2006, "The Role of Family in Family Firms," Journal of Economic Perspectives, 20 (2), 73-96.

Biasutti, R., Le Razze e i Popoli della Terra, UTET, Torino.

Bisin, A. and T. Verdier, 2001, "The Economics of Cultural Transmission and the Dynamics of Preferences," Journal of Economic Theory, 97, 298-319.

Bisin, A. and T. Verdier, 2011, "The Economics of Cultural Transmission and Socialization," Handbook of Social Economics, in J. Behnabib, A. Bisin and M.O. Jackson (eds.).

Bisin, A. and T. Verdier, in progress, "The Joint Evolution of Culture and Institutions," mimeo, New York University

Black, S. and L. Lynch, 2001, "How to Compete: The Impact of Workplace Practices and Information Technology on Productivity,"Review of Economics and Statistics, 83 (3): 434-445.

Bloom, N., R. Sadun, and J. Van Reenen, 2012, "The Organization of Firms Across Countries," Quarterly Journal of Economics, 127 (4): 1663-1705.

Bonhet I., B. Frey, and S. Huck, 2001, "More Order with Less Law: On Contract Enforcement, Trust, and Crowding" American Political Science Review, 95(1), 131-144.

Bonin, J., Jones, D. and L. Putterman, 1993, “Theoretical and Empirical Studies of Producer Cooperatives: Will Ever the Twain Meet?", Journal of Economic Literature, 31 (3): 1290-1320. 
Bortnhorst, F., Ichino, A., Kirchkamp, O., Schlag, K.H., and E. Winter, 2010, "Similarities and Differences When Building Trust: The Role of Cultures," Experimental Economics, 1(3), 260283.

Botero, J., Djankov, S., La Porta, R., Lopez-de-Silanes, and A. Shleifer, 2004, "The Regulation of Labor," Quarterly Journal of Economics, 119 (4), 1339-1382.

Botticini, M. and Z. Eckstein, 2005, "Jewish Occupational Selection: Education, Restrictions, or Minorities?" Journal of Economic History, 65(4), 922-948.

Botticini M. and Z. Eckstein, 2007, "From Farmers to Merchants, Voluntary Conversions and Diaspora: A Human Capital Interpretation of Jewish History," Journal of the European Economic Association, 5 (5), 885-926.

Bowles, S., 1998, "Endogenous Preferences: The Cultural Consequences of Markets and Other Economic Institutions," Journal of Economic Literature, 26: 75-111.

Bowles, S. and H. Gintis, 2010, "A Cooperative Species: Human Reciprocity and Its Evolution," Princeton University Press.

Boyd. R. and P. J. Richerson, 1985, Culture and the Evolutionary Process, Chicago: University of Chicago Press.

Boyd, R. and P. J. Richerson, 2005, The Origin and Evolution of Culture, Oxford University Press.

Butler, J., 2013, “Trust, Truth, Status and Identity,” EIEF, mimeo.

Butler, J., Giuliano, P., and L. Guiso, 2014, “The Right Amount of Trust,” UCLA, mimeo.

Camic, C., Gorski, P. and D. Trubek (eds.), 2004, Max Weber's Economy and Society: A Critical Companion, Palo Alto, CA: Stanford University Press.

Cantoni, D., forthcoming, "The Economic Effects of the Protestant Reformation: Testing the Weber Hypothesis in the German Lands," Journal of the European Economic Association

Carlin, B. I., Dorobantu, F., and Viswanathan, S., 2009, "Public Trust, the Law, and Financial Investment," Journal of Financial Economics, 92(3), 321-341.

Caselli, F. and N. Gennaioli, 2011, “Dynastic Management,” Economic Inquiry, 51(1), 971-996.

Charness, G., Rigotti, L., and A. Rustichini, 2007, "Individual Behavior and Group Membership," American Economic Review, 97(4), 1340-1352.

Chen, R. and Y. Chen, 2011, "The Potential of Social Identity for Equilibrium Selection," American Economic Review, 101(6): 2562-2589.

Chen, Y. and S.X. Li, 2009, "Group Identity and Social Preferences," American Economic Review, 99(1): 431-457. 
Coleman, J.S., 1988, "Social Capital in the Creation of Human Capital," American Journal of Sociology 94, 95-120.

Coleman, J.S., 1990, Foundations of Social Theory, Harvard University Press, Cambridge, Mass.

Costa, D., 2000, “From Mill Town to Board Room: The Rise of Women’s Paid Labor,” The Journal of Economic Perspectives, 14(4), 101-122

Crouch, C., 1993, Industrial Relations and European State Traditions, Clarendon Press, Oxford

Dal Bo, P., Foster, A., and L. Putterman, "Institutions and Behavior: Experimental Evidence on the Effects of Democracy," American Economic Review, 100 (5), 2205-2229.

Di Tella, R., Galiani, S.F., and E.S. Schargrodsky, 2007, “The Formation of Beliefs: Evidence from the Allocation of Land Titles to Squatters," The Quarterly Journal of Economics, 22(1), 209-241.

Dixit A., 2004, Lawlessness and Economics: Alternative Models of Governance, Princeton University Press, Princeton, N.J.

Djankov, S., La Porta, R., Lopez-de-Silanes, F., and A. Shleifer, 2002, “The Regulation of Entry,” Quarterly Journal of Economics, 117(1), 1-37.

Doepke, M. and F. Zilibotti, 2008, "Occupational Choice and the Spirit of Capitalism," The Quarterly Journal of Economics, 123(2), 747-793.

Duranton, G. and Rodriguez-Pose, A., 2009, "Family Types and the Persistence of Regional Disparities in Europe," Economic Geography, 85, 23-47.

Durlauf., S. and M. Fafchamps, 2005, "Social Capital," Handbook of Economic Growth, in Aghion, P. and S. Durlauf (eds.), Handbook of Economic Growth, North Holland: Elsevier

Easterly, W. and R. Levine, 2003, "Tropics, Germs, and Crops: How Endowments Influence Economic Development," Journal of Monetary Economics, 50(1), 3-39.

Eckel, C. and P. Grossman, 2005, "Managing Diversity by Creating Team Identity," Journal of Economic Behavior and Organization, 58: 371-392.

Engerman, S. and K. L. Sokoloff, 1997, "Factor Endowments, Institutions, and Differential Paths of Growth Among New World Economies: A View from Economic Historians of the United States," in: Harber, ed., How Latin America Fell Behind, Stanford: Stanford University Press, $260-304$.

Ertan, A., Page, T. and L. Putterman, 2009, "Who to Punish? Individual Decisions and Majority Rule in Mitigating the Free Rider Problem," European Economic Review, 53 (5): 495-511.

Fafchamps, M., 2000, "Ethnicity and Credit in African Manufacturing," Journal of Development Economics, 61, 205-235. 
Fehr, E., Fischbacher, U., Schupp, B., Von Rosenbladt, and J. Wagner, 2002, “A Nation-Wide Laboratory. Examining Trust and Trustworthiness by Integrating Behavioral Experiments into Representative Surveys," CESIFO Working Paper.

Fernandez, R., 2008, "Culture and Economics," The New Palgrave Dictionary of Economics, second edition, S.N. Durlauf and L.E. Blume (eds.), Palgrave Macmillan.

Fernandez, R., 2011, “Does Culture Matter?” in: Handbook of Social Economics, J. Behnabib, A. Bisin and M.O. Jackson (eds.).

Fernandez, R., 2013, "Cultural Change as Learning: The Evolution of Female Labor Force Participation Over a Century," American Economic Review, 103(1): 472-500.

Fernandez, R. and A. Fogli, 2010, "Culture: An Empirical Investigation of Beliefs, Work, and Fertility," American Economic Journal: Macroeconomics, 1(1), 146-177.

Fernandez-Villaverde, Greenwood, J. and N. Guner, 2013, "From Shame to Game in One Hundred Years: A Macroeconomic Model of the Raise in Premarital Sex and Its De-Stigmatization,," Journal of the European Economic Association, forthcoming.

Fershtman, C. and U. Gneezy, 2001, "Discrimination in a Segmented Society: An Experimental Approach," Quarterly Journal of Economics, 116(1): 351-377.

Fershtman, C., Gneezy, U., and F. Verboven, 2005, "Discrimination and Nepotism: The Efficiency of the Anonymity Rule," Journal of Legal Studies, 34(2), 371-396.

Figes, O., 1989, Peasant Russia, Civil Was: The Volga Countryside in Revolution: 1917-1921, Clarendon Press.

Fisher, D. H., 1989, Albion's Seed: Four British Folkways in America, New York: Oxford University Press.

Fisman, R., 2003, "Ethnic Ties and the Provision of Credit: Relationship-Level Evidence from African Firms," Advances in Economic Analysis and Policy, 3(1).

Fogli, A. and L. Veldkamp, 2011, "Nature or Nurture? Learning and the Geography of Female Labor Force Participation, Econometrica, 79(4), 1103-1138.

Francois, P. and Van Ypersele, 2009, "Doux Commerce: Does Market Competition Cause Trust?” UBC, mimeo.

Frey, B., 1998, "Institutions and Morale: The Crowding-out Effect," in Economics, Values and Organization, ed. A. Ben-Ner and L. Putterman, 437-460, New York: Cambridge University Press.

Fukuyama, F., 1995, Trust: The Social Virtues and the Creation of Prosperity, New York: Free Press. 
Galasso, V. and P. Profeta, 2012, "When the State Mirrors the Family: The Design of Pension Systems," Bocconi University, mimeo.

Galor, O. and D. Weil, 1996, "The Gender Gap, Fertility and Growth," American Economic Review, 86(3), 374-87

Geertz, C., 1973, The Interpretation of Cultures. New York: Basic Books.

Gennaioli, N. and I. Rainer, 2007, “The Modern Impact of Precolonial Centralization in Africa," Journal of Economic Growth, 12 (3), 185-234.

Giavazzi, F., Petkov, I. and F. Schiantarelli, 2014, “Culture: Persistence or Evolution”, Boston College WP 853.

Giavazzi, F., Schiantarelli, F., and M. Serafinelli, 2013. "Attitudes, Policies and Work," Journal of the European Economic Association, 11 (6), 1256-1289

Giuliano, P., 2007, “Living Arrangements in Western Europe: Does Cultural Origin Matter?” Journal of the European Economic Association, 5(5), 927-952.

Giuliano, P. and A. Spilimbergo, 2014, "Growing Up in a Recession,” Review of Economic Studies, 81 (2), 787-817.

Giuliano, P., Spilimbergo, A., and G. Tonon, “Genetic Distance, Transportation Costs, and Trade, Journal of Economic Geography, forthcoming.

Glaeser, E., Laibson, D., Scheinkman, J., and Soutter, C., 2000, “Measuring Trust," Quarterly Journal of Economics, 115, 811-846.

Glaeser, E., R. La Porta, Lopez-de-Silanes, F., and A. Shleifer, 2004, "Do Institutions Cause Growth?" Journal of Economic Growth, 9, 271-303.

Glaeser E., G. Ponzetto, and A. Shleifer, 2007, “Why Does Democracy Need Education?” Journal of Economic Growth 12, 77-99.

Gneezy, U. and D.M. Fessler, 2012, "Conflict, Sticks, and Carrots: War Increases Prosocial Punishments and Rewards, Proceedings of the Royal Society of Biology, 279, 219-233.

Gneezy, E., Leibbrandt, A., and J. List, 2012, "Ode to the Sea: On the Emergence of Social Norm," University of Chicago, mimeo.

Goldin, C., 1990, Understanding the Gender Gap: An Economic History of American Women, New York: Oxford University Press

Goldin, C. and L. Katz, 2002, “The Power of the Pill: Oral Contraceptives and Women's Career and Marriage Decisions", Journal of Political Economy, 110(4), 730-770 
Gorodnichenko, Y. and G. Roland, 2013a, "Culture, Institutions, and the Wealth of Nations," UC Berkeley, mimeo.

Gorodnichenko, Y. and G. Roland, 2013b, "Culture, Institutions, and Democratization," UC Berkeley, mimeo.

Gorodnichenko, Y. and G. Roland, 2014, "Understanding the Individualism-Collectivism Cleavage and its Effects: Lessons from Cultural Psychology," UC Berkeley, mimeo.Gorski, P., 2003, The Disciplinary Revolution: Calvinism and the Rise of the State in Early Modern Europe, Chicago: University of Chicago Press.

Greenwood, J., Seshadri, A. and M. Yorugoklu, 2005, "Engines of Liberation," Review of Economic Studies, 72(1), 109-133.

Greif, A., 1994, "Cultural Beliefs and the Organization of Society: A Historical and Theoretical Reflection on Collectivist and Individualistic Societies," Journal of Political Economy, 102(5), 912-950.

Greif, A., 2005, “Commitment, Coercion, and Markets: The Nature and Dynamics of Institutions Supporting Exchange," in: The Handbook of New Institutional Economics, C. Menard and M.M. Shirley (eds.), Norwell, Mass: Kluwer Academic Publisher.

Greif, A., 2006a, Institutions and the Path to the Modern Economy: Lessons from Medieval Trade, Cambridge University Press.

Greif, A., 2006b, "Family Structure, Institutions, and Growth: The Origins and Implications of Western Corporations," American Economic Review, 96(2): 308-312.

Greif, A. and G. Tabellini, 2012, "The Clan and the City: Sustaining Cooperation in China and Europe," IGIER WP 445.

Grosjean, P., 2011, “The Weight of History on European Cultural Integration: A Gravity Approach,” American Economic Review Papers and Proceedings, 101(3): 504-508.

Grosjean, P., forthcoming, "A History of Violence: The Culture of Honor as a Determinant of Homicide in the U.S. South," Journal of the European Economic Association

Gruber, J. and D. Hungerman, 2008, “The Church Versus the Mall: What Happens When Religion Faces Increased Secular Competition?” The Quarterly Journal of Economics, 123(2), 831-862.

Guiso, L., Sapienza, P., and L. Zingales, 2004, “The Role of Social Capital in Financial Development," American Economic Review, 94(3), 526-556.

Guiso, L., Sapienza, P., and L. Zingales, 2006, “Does Culture Affect Economic Outcomes?” Journal of Economic Perspectives, 20(2): 23-48. 
Guiso, L., Sapienza, P., and L. Zingales, 2008a, “Trusting the Stock Market,” Journal of Finance, 63(6), 2557-2600.

Guiso, L., Sapienza, P., and L. Zingales, 2008b, "Social Capital as Good Culture," Journal of the European Economic Association, Vol. 6 (2-3), 295-320.

Guiso, L., Sapienza, P. and L. Zingales, 2009, “Cultural Biases in Economic Exchange?” Quarterly Journal of Economics, 124(3), 1095-1131.

Guiso, L., Sapienza, P., and L. Zingales, 2011, “Civic Capital as the Missing Link," Handbook of Social Economics, Vol. 1a, J. Behhabib, A. Bisin, and M.O. Jackson (eds.).

Guiso L. Sapienza P., and L. Zingales, 2013, "Long-Term Persistence,” Northwestern University, mimeo.

Heine, S. J., 2008, Cultural psychology, W.W. Norton \& Company

Heine, S. J., 2010, “Cultural Psychology” in Handbook of Social Psychology, D. Fiske, D. Gilbert and G. Lindzey.

Henrich, J., Boyd, R., Bowles, S., Camerer, C., Fehr, E., Gintis, H. and R. McElreath, 2001, "In Search of Homo Economicus: Behavioral Experiments in 15 Small-Scale Societies," American Economic Review, 91(2): 73-78.

Herrmann, B., Thoni, C., and Gachter, S., 2008, “Antisocial Punishment Across Societies,” Science, 319(5868), 1362-1367.

Hofstede, G., 2001, Culture's Consequences: Comparing Values, Behavior, and Organizations Across Nations, second edition. Sage Publications.

Jackson K., (2013) "Contract Enforceability and the Evolution of Social Capital," The Journal of Economic Law and Organizations, 29, 60-77.

Kaplow, L. and S. Shavell, 2007, "Toward a Theory of a Moral System That Optimally Channels Behavior," Journal of Political Economy, 115, 494-514.

Knack, S. and P. Keefer, 1997, "Does Social Capital Have an Economic Payoff? A Cross-Country Investigation," Quarterly Journal of Economics, 112(4), 1252-1288.

Kohn, M. et al., "Position in the Class Structure and Psychological Functioning in the United States, Japan, and Poland," American Journal of Sociology, 95(4), 964-1008.

Kuran, T., 2005, "The Absence of the Corporation in Islamic Law: Origins and Persistence," American Journal of Comparative Law, 53, 785-834.

La Ferrara, E., 2010, “Family and Kinship Ties in Development: An Economist's Perspective," in: Culture, Institutions and Development, J.P. Platteau (ed.), Routledge. 
La Ferrara, E. and A. Milazzo, 2011, “Customary Norms, Inheritance, and Human Capital. Evidence from a Reform of the Matrilineal System in Ghana," Bocconi University, mimeo.

Laitin, D., 2007, Nations States and Violence, Oxford University Press, Oxford, U.K.

Landes D., 1998, The Wealth and Poverty of Nations, Norton, New York.

La Port, R., Lopez-de-Silanes, F., Pop-Eleches, C. and A. Shleifer, 2004m "Judicial Checks and Balances", Journal of Political Economy, 112 (2), 445-470.

La Porta R., Lopez-de-Silanes, F., Shleifer, A., and R. Vishny, 1997, “Legal Determinants of External Finance," Journal of Finance, 52(3), 1131-1150.

La Porta R., Lopez de Silanes, F. Shleifer, A., and R. Vishny, 1998, “Law and Finance," Journal of Political Economy, 106 (6), 1113-1155.

La Porta R., Lopez-de-Silanes, F., Shleifer, A., and R. Vishny, 1999, “The Quality of Government,” Journal of Law Economics and Organization, 15(1), 222-279.

La Porta R., Lopez-de-Silanes, F., Shleifer, A., and R. Vishny, 2002, “Government Ownership of Banks," The Journal of Finance, 57(1), 265-301.

Lee, W. and J. Roemer, 2006, "Racism and Redistribution in the United States: A solution to the problem of American exceptionalism", Journal of Public Economics, 1027-1052.

Levine, D. and L. Tyson, 1990, "Participation, Productivity, and the Firm's Environment," in Paying for Productivity: A Look at the Evidence, ed. A. S. Blinder, 183-237, Center for Economic Progress and Employment Series. Washington, DC: Brookings Institutions.

Licht, A., Goldschmidt, C. and S. Schwartz, "Culture, Law and Corporate Governance," 2005, International Review of Law and Economics, 25, 229-255.

Lipset, S. M., 1959, "Some Social Requisites of Democracy: Economic Development and Political Legitimacy", American Political Science Review, 53, 69-105.

Lipset, S. M. and Marks, G. W., 2001, “It Didn’t Happen Here: Why Socialism Failed in the United States", Norton, New York.

Locke, R.M., "Building Trust," in: Mezzogiorno and Politiche di Sviluppo, A. Flora (ed.), Naples: Edizioni Scientifiche Italiane, 109-133.

Luke, N. and K. Munshi, 2006, "New Roles for Marriage in Urban Africa: Kinship Networks and the Labor Market in Kenya," Review of Economics and Statistics, 88(2), 264-282.

Luttmer, E., 2001, “Group Loyalty and the Taste for Redistribution”, Journal of Political Economy, 109, $500-528$ 
Luttmer, E. and M. Singhal, 2011, "Culture, Context, and the Taste for Redistribution," American Economic Journal: Economic Policy, 3(1): 157-179.

Macfarlane, A., 1978, The Origins of English Individualism: The Family Property and Social Transition, WileyBlackwell.

Malmendier, U., and S. Nagel, 2011, "Depression Babies: Do Macroeconomic Experiences Affect Risk-Taking?" Quarterly Journal of Economics, 126, 373-416.

Markus, H. R. and Kitayama, S., 1991, "Culture and the Self: Implications for Cognition, Emotion and Motivation", Psychological Review, 98(2), 224-253.

Michalopoulos, S. and E. Papaioannou, 2013,a "Pre-Colonial Ethnic Institutions and Contemporary African Development," Econometrica, 81(1), 113-152.

Michalopoulos, S. and E. Papaioannou, 2014, "National Institutions and Subnational Development in Africa," 2013, Nannicini, T., Stella, A., Tabellini, G., and U. Troiano, 2012, "Social Capital and Political Accountability," American Economic Journal: Economic Policy, 5, 222-250.

Murrell, P. and M. Schmidt, 2011, “The Coevolution of Culture and Institutions in Seventeenth Century England", University of Maryland, mimeo.

North, D., 1990, Institutions, Institutional Change, and Economic Performance, Cambridge University Press, Cambridge.

North, D., 1991, “Institutions”, Journal of Economic Perspectives, Vol. 5(1), 97-112.

Nunn, N., 2009, “The Importance of History for Economic Development," Annual Review of Economics, 1(1), 65-92.

Nunn, N., 2013, "Historical Development," in: Handbook of Economic Growth, Vol. 2, Aghion, P. and S. Durlauf (eds.), North-Holland.

Oyserman, D., Conn, H. M. and Kemmelmeier, M., 2002, "Rethinking Individualism and Collectivism: Evaluation of Theoretical Assumptions and Meta-Analyses", Psychological Bulletin, 128, 3-72

Padro-Y-Migel, G., Qian, N., and Y. Yao, 2013, "Making Democracy Work: The Effect of Social Capital on Elections and Public Goods in China," Yale University, mimeo.

Persson, T. and G. Tabellini, 2003, The Economic Effects of Constitutions, Cambridge, MA: The MIT Press.

Peisakhin, L., 2010, "Living Historical Legacies: The "Why" and "How” of Institutional Persistence," Yale University, mimeo. 
Piketty, T., 1995, "Social Mobility and Redistributive Politics," The Quarterly Journal of Economics, 110, $551-584$.

Pinker, S., 1997, How the Mind Works, New York: W. W. Norton \& Company.

Pinotti, P., 2012, “Trust, Regulation and Market Failures," Review of Economics and Statistics, 94(3), $650-658$.

Pipes, R., 1994, Russia under the Bolshevik Revolution, Vintage Books, New York

Platteau, J.P., 2000, Institutions, Social Norms, and Economic Development, Academic Publishers and Routledge.

Putnam, R., Leonardi, R., and R.Y. Nanetti, 1993, Making Democracy Work, Princeton, NJ: Princeton University Press.

Putnam, R., 2000, Bowling Alone: The Collapse and Revival of American Community, New York: Simon and Schuster.

Roland, G., 2004, “Understanding Institutional Change: Fast-Moving and Slow-Moving Institutions," Studies in Comparative International Development, 38(4), 109-131.

Schelling, T., 1960, The Strategy of Conflict, Cambridge: Harvard University Press

Schwartz, S.H., 1992, "Universals in the Content and Structure of Values: Theory and Empirical Tests in 20 Countries," in: Advances in Experimental Social Psychology, M. Zanna (ed.), New York: Academic Press.

Shiller, R., Boycko, M., Koborov, M., Winter, S., and T. Schelling, 1992, "Hunting for Homo Sovieticus: Situational Versus Attitudinal Factors in Economic Behavior," Brookings Papers on Economic Activity, 1, 127-194.

Stulz, R. and R. Williamson, 2003, "Culture, Openness and Finance”, Journal of Financial Economics, 70 (3), 313-349.

Sombart, W., 1976, Why Is There No Socialism in the United States? White Plains

Sutter, M., Haigner, S. and M. Kocher, 2010, "Choosing the Carrot or the Stick? Endogenous Institutional Choice in Social Dilemma Situations," Review of Economic Studies, 77 (4): 15401566.

Tabellini, G., 2008a, "Institutions and Culture," Journal of the European Economic Associations, 6(2-3), 255-294.

Tabellini, G., 2008b, "The Scope of Cooperation: Values and Incentives," Quarterly Journal of Economics, 123(3), 905-950. 
Tabellini, G., 2010, "Culture and Institutions: Economic Development in the Regions of Europe," Journal of the European Economic Association, 8(4), 677-716.

Todd, E., 1983, The Explanation of Ideology: Family Structures and Social Systems, Basic Blackwell, New York.

Todd, E., 1990, L'Invention de l'Europe, Seuil, Paris.

Tyran, J. R. and L. Feld, 2006, "Achieving Compliance when Legal Sanctions are Non-deterrent", Scandinavian Journal of Economics, 108 (1): 135-156.

Uslaner, E., 2005, “Trust as a Moral Value," in: Handbook of Social Capital, D. Castiglione, J.W. van Deth, and G. Wolleb (eds.), Oxford University Press.

Voors, M., Nillesen, E.E., Verwimp, P., Bulte, E. H., Lesink, R., Van Soest, D., et al., 2012, “Violent Conflict and Behavior: A Field Experiment in Burundi," American Economic Review, 102(2), 941-964.

Weber, M., Economy and Society, 1978, G. Roth and C. Wittich (eds.), Berkeley: University of California Press.

Whitt, S. and R.K. Wilson, 2007, "The Dictator Game, Fairness, and Ethnicity in Postwar Bosnia," American Journal of Political Science, 51 (3), 655-668.

Willinger, M., Keser, C., Lohmann, C., and J.C. Usunier, 2003, “A Comparison of Trust and Reciprocity Between France and Germany: Experimental Investigation Based on the Investment Game," Journal of Economic Psychology, 24(4), 447-466.

Winick, C. (1956), Dictionary of Anthropology, New York: Philosophical Library.

Wyatt-Brown, B., 1982, Southern Honor: Ethics and Behavior in the Old South, New York: Oxford University Press

Wyatt-Brown, B., 2001, The Shaping of Southern Culture: Honor, Grace and War, 1760s-1890s, Chapel Hill: University of North Carolina 
Figure 1: Geographical Distribution of Cultural Values

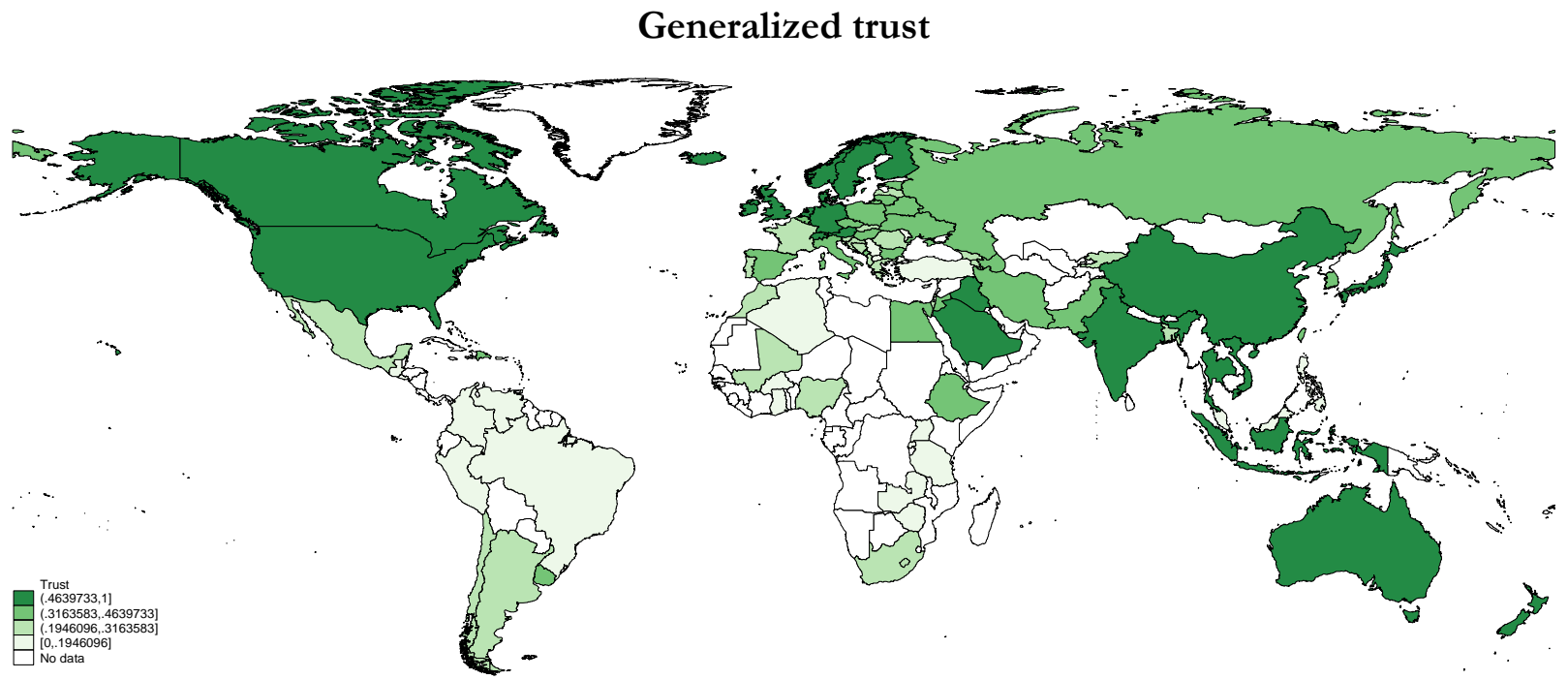

Individualism

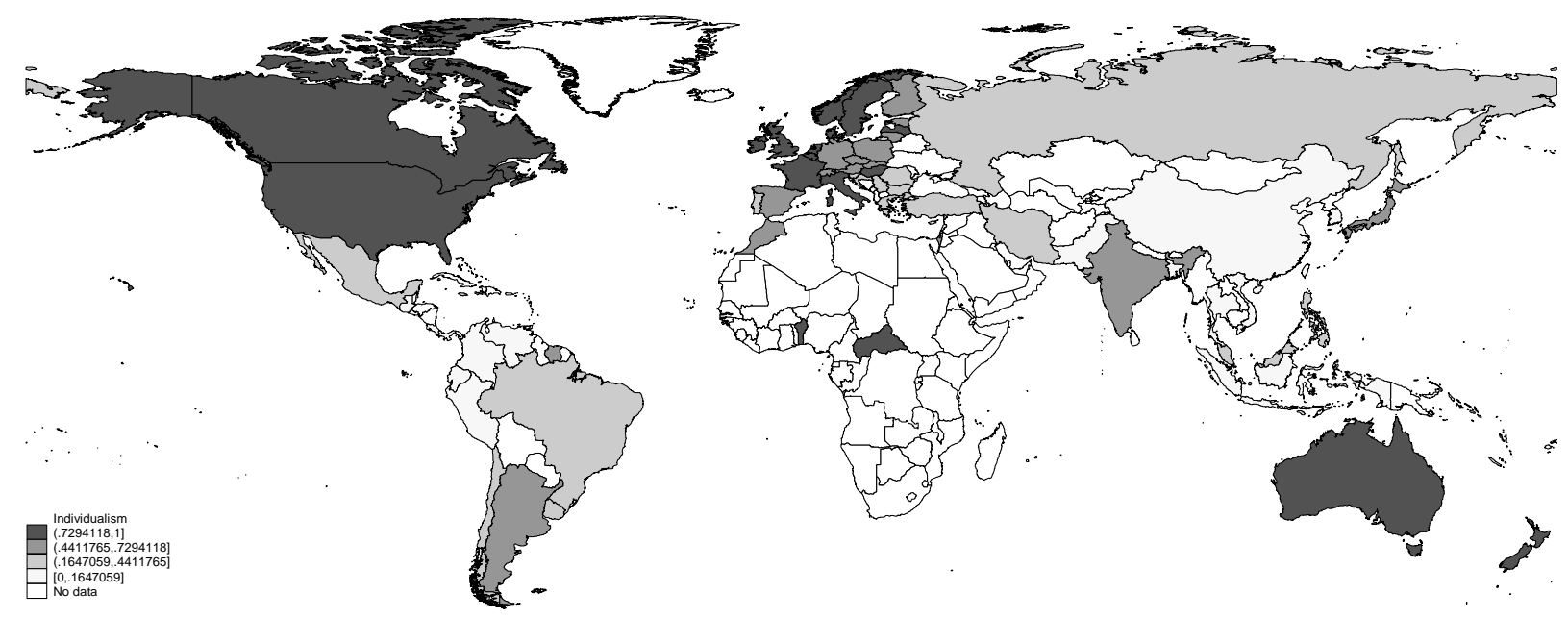


Family Ties

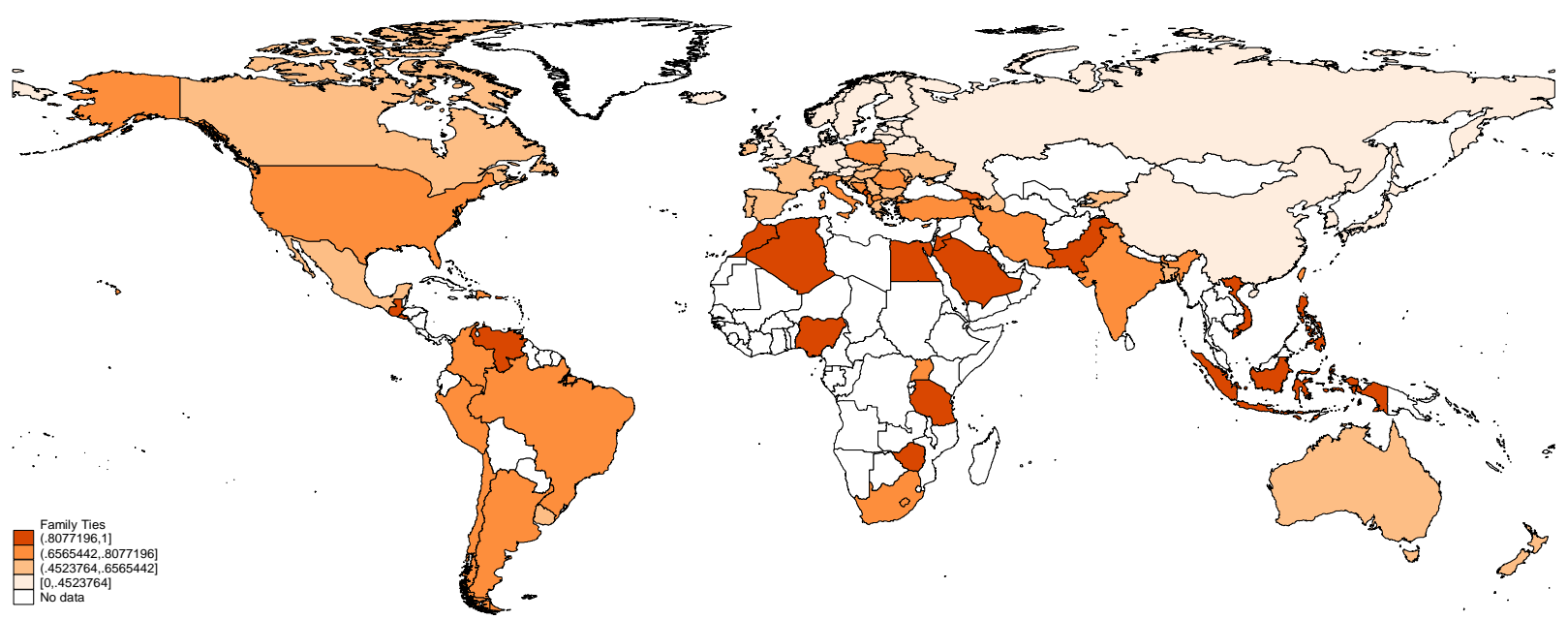

Generalized Morality

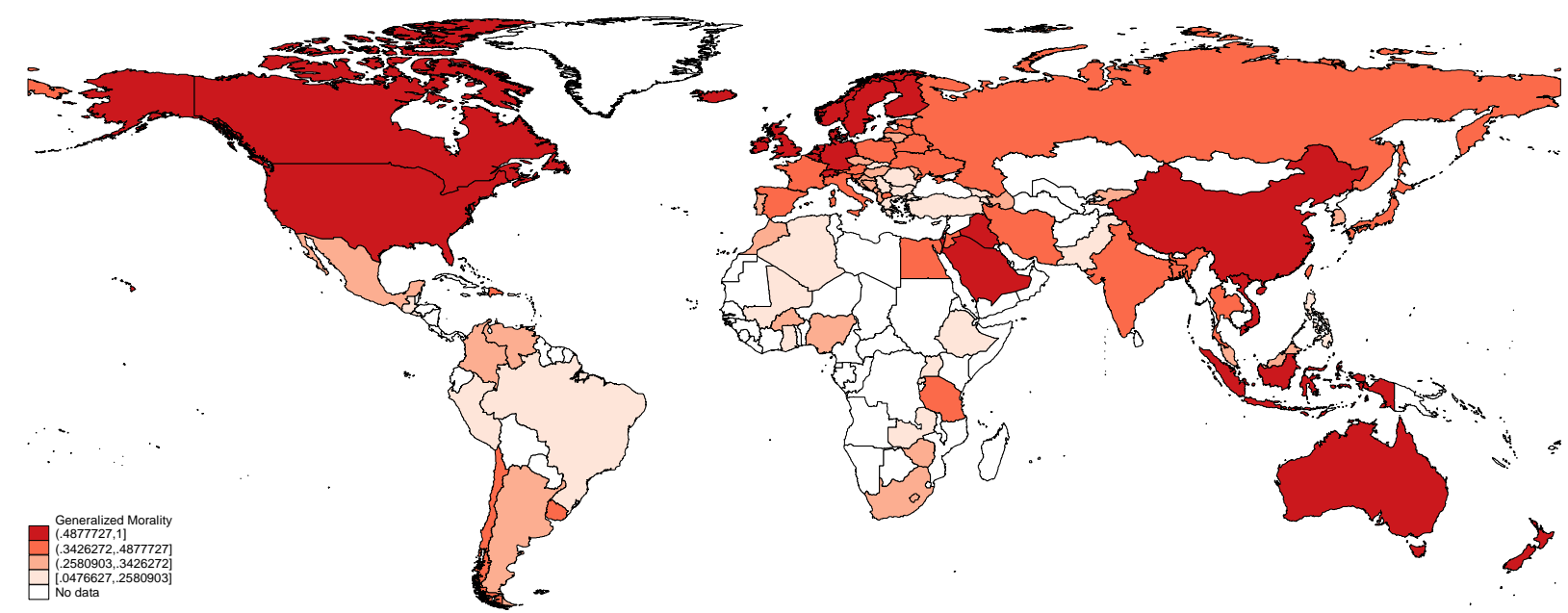

Work-Luck Beliefs

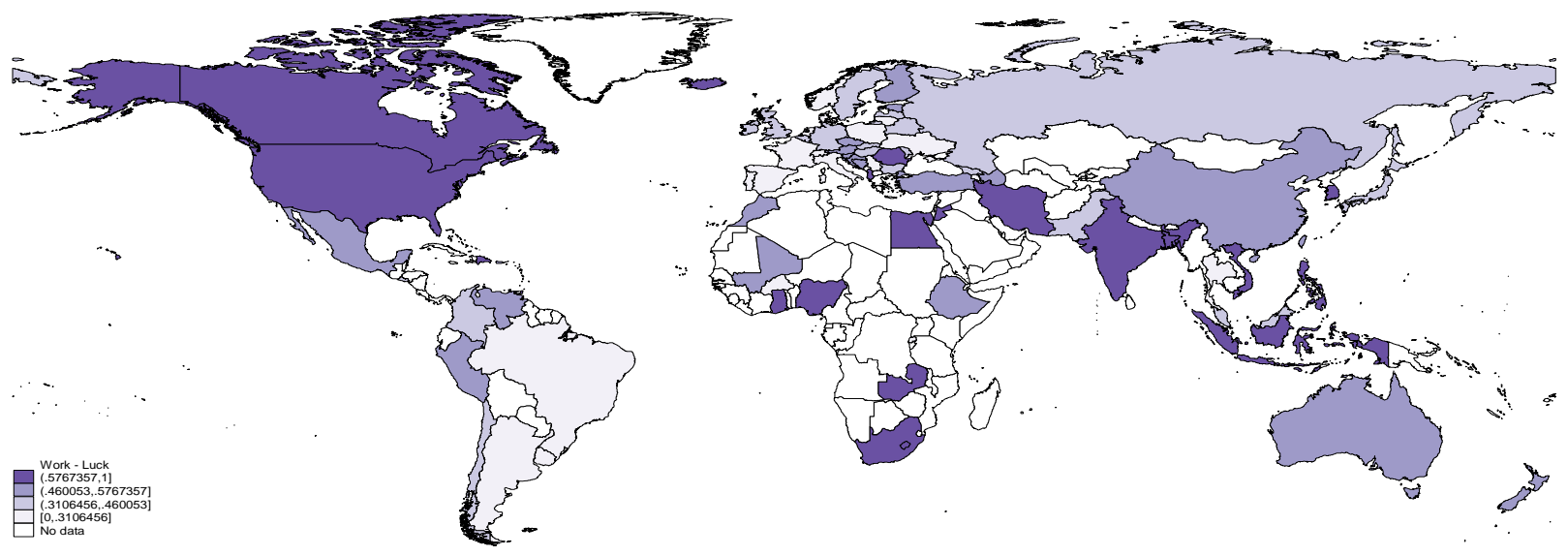

